\title{
Mechanical and Gas Barrier Properties of Polypropylene Layered Silicate Nanocomposites: A Review
}

\author{
V. Mittal* \\ The Petroleum Institute, Chemical Engineering Department, Abu Dhabi, UAE
}

\begin{abstract}
Polypropylene owing to its apolar nature suffers from compatibility problems with clay, which is partially polar even after the surface modification with alkyl ammonium ions. To circumvent this limitation, polypropylene nanocomposites have been synthesized by using two methodologies: a) partial polarization of the matrix by the addition of low molecular weight compatibilizer which owing to its amphiphilic nature acts towards compatibilizing the polymer and inorganic phases and b) by completely organophilizing the clay surface by using filler surface modification with long alkyl chains and with higher chain density. The addition of compatibilizer leads to better filler delamination and better mechanical performance, however, the modulus decreases after a certain extent of compatibilizer owing to plasticization of matrix. The permeation properties were observed to be affected negatively owing to mismatch of the polar compatibilizer chains with apolar surface modification chains. The second methodology, on the other hand, leads to simultaneous improvement of mechanical and gas barrier properties. Better organophilization of the filler surface reduces the attractive forces between the platelets further and increases their potential of exfoliation in the polymer matrix. Other advanced surface modifications dealing with chemical reactions on the surface of the filler have also been reported to increase the basal plane spacing.
\end{abstract}

Keywords: Clay platelets, mechanical performance, oxygen barrier, delamination, plasticization, compatibility, thermal stability, modeling, grafting, polymerization, esterification, melt mixing, physical adsorption.

\section{INTRODUCTION}

Polypropylene is a polymer of choice for a large number of applications. It has a low density of $0.90 \mathrm{~g} / \mathrm{cm}^{3}$, high crystallinity as well as low cost. The products made out of polypropylene can also withstand high temperature, boiling water etc. owing to its higher softening point and dimensional stability. To expand the spectrum of applications of polypropylene, composites by the incorporation of inorganic fillers in the polymer matrix have been generated for long. Different types of inorganic fillers like silica particles, talc, mice, clay, vermiculite etc. have been commonly used. Conventional composites required the addition of a large amount of filler to achieve significant enhancement in the composite properties. These higher amounts of fillers with high density caused the conventional composites to become bulky as well as hindered the optical transparency of the polymer which is an important requirement for applications in packaging industry. By the advent of polymer nanocomposites, in which the layered silicate high aspect ratio clay platelets of $1 \mathrm{~nm}$ thickness (mostly montmorillonite) could be dispersed at the nanoscale in the polymer matrix, tremendous improvements in the composite properties were reported at very low filler volume fractions $[1,2]$. The layered silicate filler platelets are polar in nature and have alkali metal or alkaline earth metal cations adsorbed on the surface which owing to electrostatic forces of attraction lead to the formation of thick

*Address correspondence to this author at the Petroleum Institute, Chemical Engineering Department, Abu Dhabi, UAE; Tel: 0097126075491; E-mail:vmittal@pi.ac.ae tactoids of platelets held together thus forming interlayers in between. The compatibilization between the polymer and inorganic phases was achieved by suitable surface modifications of the filler which are generally achieved by exchanging the alkali metal or alkaline earth metal cations on the surface of filler platelets with long chain alkyl ammonium ions. When the platy filler is dispersed in the polymer matrix at nanoscale, it leads to the generation of a large extent of interfacial contacts between the polymer and the filler which leads to the generation of altogether different morphology at the interface and better stress transfer, heat transfer and barrier to gases or water vapor is achieved. Owing to the nanoscale dispersion of the thin filler platelets in the polymer matrix, the required property enhancements are thus achieved at low filler volume fractions which helps the composite to retain optical clarity as well as low density. Polar polyamide based nanocomposites were initially reported by Toyota researchers where owing to better match between the polar polymer matrix and polar filler substrates, the filler delamination in the matrix was very efficient $[1,2]$. Nanocomposites based on other polar polymers have also been reported with enhanced mechanical, thermal and gas barrier properties [3-8]. As polypropylene has a large number of commercial applications, it is also of interest to achieve nanocomposites of polypropylene in order to further enhance the spectrum of its applications as well as to enter the market of engineering plastics. The incorporation of platy filler can be particularly beneficial in improving the gas permeation properties as the platelets increase the mean path length of the permeant molecules diffusing through the composite. Being non-polar in nature, however, the intercalation of polypropylene chains in the partially polar filler interlayers 
and subsequent filler delamination is thermodynamically unfavorable. As a result, a complete delamination of the filler in the polypropylene matrix is not achieved by simple melt mixing of the polymer and modified clay. This thus has also resulted in non-optimal enhancement of properties which are generally dependant on the morphology of the composites. Advances in the filler delamination in the polymer have been made by either polarizing the polymer matrix to improve interactions with the filler or by organophilizing the filler better to achieve entrapment of the filler platelets in polymer by shear. In this regard, advanced filler surface modifications which provide increased potential of extensive filler exfoliation in the polymer matrix have also been developed. These advances are detailed in the forthcoming sections with a focus of developing polypropylene nanocomposites with better mechanical as well as gas barrier properties simultaneously. The simultaneous enhancement of mechanical and gas barrier properties need to be stressed because the barrier properties of nanocomposites have generally been neglected and it is assumed that the enhancement in the mechanical performance of the composites leads to automatic improvement in the gas permeation resistance, which may not be necessarily true.

\section{THEORETICAL AND EXPERIMENTAL ASPECTS}

Toyota researchers $[1,2]$ reported the synthesis of the polyamide nanocomposites by monomer intercalation method. In this method, the monomer is first intercalated into the clay interlayers followed by polymerization which leads to expansion of the filler interlayers by more and more polymer intercalating during the polymerization. To generate polymer nanocomposites with already formed high molecular weight polymers, i.e., without generating the polymer in presence of filler, Giannelis and co-workers $[9,10]$ reported the technique of melt mixing in which the polymer is melted at high temperature, to which the filler is then added and mixed under shear. This method is beneficial as it is very compatible with the common polymer processing operations and thus has become a preferred method for nanocomposite synthesis. The other reported method of solvent intercalation also requires the use of solvent which is not feasible in many cases owing to processing or economic constraints.

Lattice model theory [11] was also used to understand the intercalation of molten polymer chains in the filler interlayers. The authors suggested that the intercalation of polymer chains in the interlayers was governed by the interplay of entropic and enthalpic factors. The authors defined the enthalpy of mixing to consist of two components: apolar unfavorable interactions arising from the interaction of polymer chains with the modifier chains (apolar) ionically bound to the filler surface and polar interactions which are result of interaction of polar filler surface with the polymer chains. It was also reported that the mixing of the polymer and filler can be improved by maximizing the favorable interactions between the polymer chains and layered silicate surface and on the same hand by minimizing the unfavorable interactions between the polymer chains and surface modification molecules immobilized on the filler surface. However, these considerations are valid for polar polymers as in the case of polypropylene, there is no interaction between the apolar polymer chains and the polar layered silicate surface. On the other hand, the interactions between the polar layered silicate surface and the apolar polypropylene chains can be improved if the polymer matrix is also partially polarized e.g. by the addition of low molecular weight compatibilizers or surfactants to the matrix. These surfactants or compatibilizers are amphiphilic in nature as these can interact with the polar filler surface as well as mix well with the apolar polymer chains thus bringing out better compatibility between the composite phases, the compatibilizer is observed to intercalate the filler interlayers first with possible subsequent intercalation of polypropylene chains. Other theoretical studies [12-14] implying the use of self consistent models have also predicted similarly that in the absence of an interactions of the apolar polyolefin chains with the filler, the best microstructure expected is the intercalated morphology without exfoliation of the filler. These studies also predicted that the thermodynamic state of the system could be enhanced by the use of filler surface modifications which are longer in length as it would push the filler platelets further apart thus reducing the electrostatic forces of attraction holding the platelets together. Thus, even in the absence of any attractive forces between the polymer and filler, the use of longer chain surface modification was opined to improve delamination of the filler. The grafting density of the immobilized modifier chains on the surface of the filler was reported to be a significant factor which needed to be controlled as the density should not be too low or too high. Too low density would not allow the surfactant chains to have slant position on the surface thus the molecules may lie parallel to the filler surface thus keeping the forces between the platelets intact. Too high density, on the other hand, was predicted to resist mixing with the polymer chains as no space would be available for the polymer chains to interact with the surface. But this prediction again suits for the polar polymer as in the case of apolar polypropylene, such interactions are not feasible, except the case when the polypropylene matrix is partially polarized by the addition of compatibilizers. Thus, in the case of polypropylene without the addition of compatibilizer, one can expect that by increasing the grafting density of the surfactant molecules on the surface, once can have better interlayer spacing between the platelets which subsequently leads to weaker attraction forces between them, thus, these platelets can be expected to be delaminated only by the action of shear when compounded with the polymer at high temperatures. Thus, a partial delamination of the filler can still be expected even when there are no thermodynamic forces favorable for the intercalation of polymer chains in the filler interlayers. The systems in this case would resemble more like of kinetic entrapment of the filler platelets in the polymer melt.

Thus, based on the above mentioned considerations, two different routes for the synthesis of polypropylene nanocomposites have been reported. The first, which is also the most commonly used route, is achievement of the partial polarization of the polypropylene matrix by addition of low molecular weight compatibilizers. The generally used compatibilizer for polypropylene nanocomposite systems has been polypropylene-g-maleic anhydride. As mentioned above, owing to its amphiphilic nature, these copolymers can interact with both the phases of the composites and help to compatibilize them together. The second route, where the addition of compatibilizer is not performed, is based on complete organophilization of the filler by modifying the surface with long alkyl 
chain modifications or with modifications with higher chain density or also by properly exchanging the conventional alkyl ammonium ions on the surface so that there is no excess of the surface modification molecules left on the surface which can degrade at low temperatures during the compounding process. This route thus focuses on the delamination of the filler only with shear.

Apart from exchanging pre-formed alkyl ammonium chains on the surface of the filler platelets, the other routes of surface modification of the filler to reduce the interaction forces between the platelets to minimum have also been developed. These routes are necessary because the pre-formed alkyl ammonium based modifications cannot be long enough to eliminate the attractive forces between the platelets owing to their solubility constraints. Thus, to circumvent these limitations, two step modification processes have been used, in such modification processes, the surface is first exchanged with an initiator or monomer group containing surface modification of easily exchangeable length. Then this reactive group is used to polymerize the externally added monomer so that to graft the polymer chains on the surface. This way longer chains can be attached to the filler surface an there is also no solubility constraint. Physical adsorption of the polymer chains on the surface of already modified montmorillonite platelets has also been reported. In this case, the physical adsorption of the polymer chains as a second step covers the spaces left after first modification reactions and, thus, reduces the attractive forces between the filler platelets.

Also, it should be noted that the filler platelets have been conventionally modified with ammonium based alkyl chains to synthesize the polypropylene nanocomposites. As the polypropylene nanocomposites are generated by melt compounding the filler with the polymer melt at high temperature, thus, the thermal stability of the surface modification should be high. However, the alkyl ammonium ions have the onset of degradation around the same temperature used for compounding and it has been reported that the degradation of even a small amount of filler surface modification can bring about a significant deterioration at the interface between the polymer and filler. The degradation products can also interact with the polymer thus degrading its molecular weight and mechanical performance, and as the interfacial interactions are disturbed, it also negatively impacts the barrier performance of the nanocomposites. Thus, it is also of importance to control the thermal degradation of the filler modification and subsequently the polymer. Polymer compounding temperature should be chosen so that is high enough to melt the polymer and the polymer viscosity is suitable to mix well with the modified filler, but on the other hand, it is not too high to thermally degrade the system. Similarly the compounding time also should be so that it allows homogenous mixing of filler and polymer, but on the other hand, one should not compound for too long so as to induce extensive thermal degradation of the organic matter. Other possibility is the use of more thermally stable modifications like modification based on imidazolium phosphonium, pyridinium ions etc. instead of ammonium. Modifications based on these thermally stable ions have higher onset of degradation temperatures and can resist the thermal degradation of the modification and hence polymer even when higher compounding temperatures or longer compounding times are used. The forthcoming sections would focus on the ammonium based as well as imidazolium based modifications for the fillers and subsequently synthesis of their composites with polypropylene and their mechanical and oxygen barrier properties. Further specialty modifications generating increased extent of organic matter in the filler interlayers would also be mentioned.

Modeling of composite properties is also important in order to predict the composite behavior, to fine tune the synthesis process and to design the materials according to need. There are a number of methods available to model the composite properties: micro-mechanic models, design of experiment methodologies, finite element methods etc. The end section would focus on the use of these methods to predict the properties of both compatibilized as well as noncompatibilized polypropylene nanocomposites.

\section{NANOCOMPOSITES WITH AMMONIUM BASED FILLER MODIFICATIONS}

As mentioned above, the compatibilizers like polypropylene-g-maleic anhydride (PP-g-MA) have been extensively used for the synthesis of polypropylene nanocomposite, as observed from a number of studies [15-25]. The molecular weight of the compatibilizer was reported not to affect the composite properties. The filler delamination was observed to enhance as a function of amount of compatibilizer on the system. The extent of maleic anhydride grafting on the polypropylene chains was a deciding factor for the compatibility between the polymer and compatibilizer.

In one such study on the polypropylene nanocomposites, different compatibilizers were used in order to study the effect of the characteristics of the compatibilizers on the microstructure and properties of nanocomposites [26]. Filler modified with dioctadecyldimethylammonium was used and the amount of filler was fixed at $3 \mathrm{vol} \%$ in order to quantify the effect of compatibilizers. The first compatibilizer, PP-gMA1 had a high molecular weight owing to its low MFI and its maleic anhydride content was low. The second compatibilizer PP-g-MA2 had a number average molecular weight of 3900 (weight average of 9100) and had 4 wt \% of maleic anhydride content. It had thus 3.7 MA units per polymer chain, thus, making it a high MA compatibilizer. It was also of interest to study the performance of block copolymer with grafted copolymer on the composite properties. As the block copolymers of polypropylene with other polar polymers are not available, PP-b-PPG (polypropylene glycol) was synthesized by the reaction of PP-g-MA2 with polypropylene glycol monobutyl ether. Although the resulting block copolymer was generated from a grafted copolymer and thus is not strictly a diblock copolymer, but its performance can be related more to a block copolymer than the grafted copolymer. This compatibilizer also had the maximum polarity of the three compatibilizers. A low value of compatibilizer/OMMT weight ratio of 0.16 was used in the composites so that the compatibilizer does not affect significantly the crystal structure of polymer.

The basal plane values of the filler were observed to marginally improve on the addition of compatibilizers indicating intercalation of the polymer in the interlayers. Apart from that, the polarity of the compatibilizers was also significant as the increase in the basal plans spacing was proportional to the polarity. It is expected as the filler interlayers 
Table 1. Tensile Properties of Polymer and 3 vol\% Dioctadecyldimethylammonium Modified Filler-Polypropylene Nanocomposites with and without 2 wt\% of Different Compatibilizers. Reproduced from Reference 26 with Permission from Wiley

\begin{tabular}{|c|c|c|c|c|}
\hline $\begin{array}{c}\text { Compatibilizer } \\
\mathbf{( 2} \mathbf{w t} \%)\end{array}$ & $\begin{array}{c}\text { Tensile Modulus }^{\mathbf{a}} \\
\text { MPa }\end{array}$ & $\begin{array}{c}\text { Yield Stress }^{\mathbf{b}} \\
\text { MPa }\end{array}$ & $\begin{array}{c}\text { Yield Strain }^{\mathbf{c}} \\
\mathbf{( \% )}\end{array}$ & $\begin{array}{c}\text { Stress at Break }^{\mathbf{d}} \\
\text { MPA }\end{array}$ \\
\hline \hline Pure PP & 1510 & 36 & 9.4 & 29 \\
\hline No compatibilizer & 2016 & 28 & 4.3 & 26 \\
\hline PP-g-MA1 & 2131 & 28 & 4.3 & 23 \\
\hline PP-g-MA2 & 2124 & 28 & 3.3 & 26 \\
\hline PP-b-PPG & 2088 & 27 & 26 \\
\hline
\end{tabular}

${ }^{\mathrm{a}}$ Relative probable error $5 \%$.

${ }^{\mathrm{b}}$ Relative probable error $2 \%$.

${ }^{\mathrm{c}}$ Relative probable error $5 \%$.

${ }^{\mathrm{d}}$ Relative probable error $15 \%$.

are still partially polar after the surface modification and they attract the polar molecules. The characterization of morphology by transmission electron microscopy also indicated the enhanced delamination of the filler on the addition of compatibilizers. However, as reported by X-ray diffraction, complete filler exfoliation was not observed and the morphology was mixed with the presence of both exfoliated and intercalated (in varying degrees) platelets. Table 1 shows the tensile properties of the compatibilized nanocomposites in comparison with pure polymer as well as composite without compatibilizer. Tensile modulus was enhanced on the addition of compatibilizers owing to enhanced delamination of filler in the matrix. The other properties were observed to decrease as compared to pure polymer owing to the presence of filler tactoids as well as strain hardening of the polymer chains trapped in the filler interlayers. The yield strain and breaking stress were occasionally higher than in the case of composite without compatibilizer owing to the weak plasticizing effect of the compatibilizers.

The oxygen permeation is generally expected to decrease with filler exfoliation. However, oxygen permeation through the composite films was observed to increase in the case of composites with PP-g-MA1 and PP b-PPG compatibilizers, whereas it was almost unchanged in the case of PP-g-MA2. Thus, automatic assumption of improvement of oxygen barrier with mechanical properties does not hold true as the deterioration of the permeation behavior happened parallel to improvement in mechanical performance. The reason behind the deterioration of the barrier properties can be related to the compatibility of the treated clay with the compatibilizer molecules. Although the compatibilizer molecules improve the filler delamination by adsorbing on the surface but their incompatibility with the filler surface modification can lead to the generation of microvoids or increased free volume at the interface. Thus. the decrease in the oxygen permeation owing to filler exfoliation is negated by the increase in permeation owing to voids or increased free volume. Similar effects have also been seen for other polymer nanocomposite systems [27, 28]. Mechanical properties owing to their macro nature seem to remain independent or less affected by such micro voids.

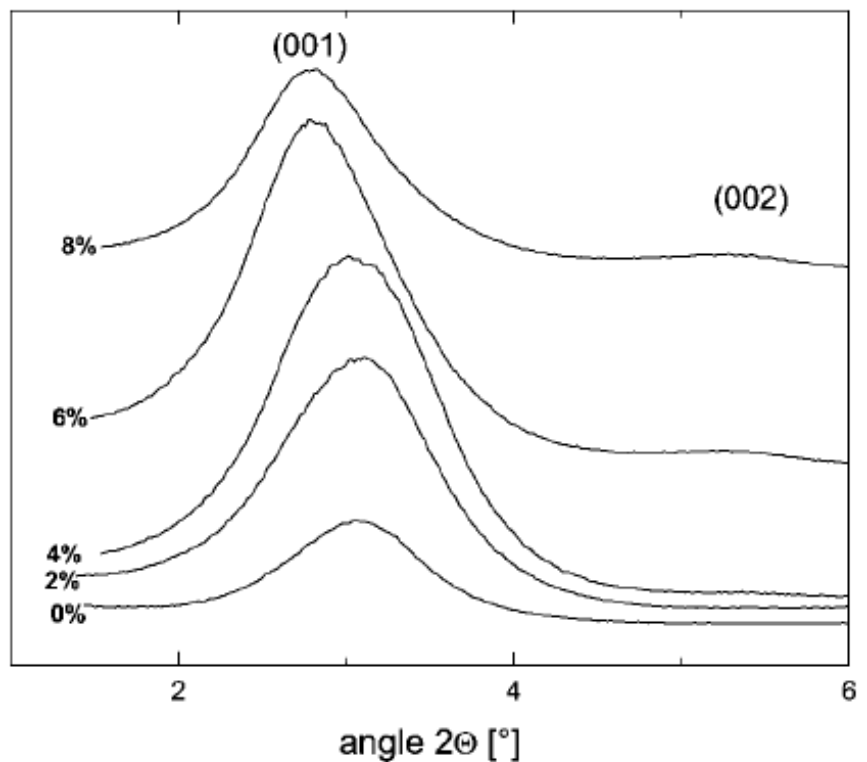

Fig. (1). X-ray diffractograms of the polypropylene nanocomposites with increasing amount of PP-g-MA2 compatibilizer, while keeping the amount of filler constant to $3 \mathrm{vol} \%$. Reproduced from reference 26 with permission from Wiley.

To further elucidate the effect of compatibilizer on the composite microstructure and properties, the composites with increasing extent of compatibilizer were synthesized. Fig. (1) shows the X-ray diffractograms of the composites with 2, 4, 6 and $8 \mathrm{wt} \%$ of the PP-g-MA2 compatibilizer. The filler diffraction peaks were observed to shift to lower angles as a function of compatibilizer weight fraction indicating higher extents of intercalation. The presence of diffraction peak even in the case of composites with $8 \mathrm{wt} \%$ compatibilizer indicated that the complete exfoliation of the filler could still not be achieved. Also, the increase in basal plane spacing was abrupt after $4 \mathrm{wt} \%$ of compatibilizer indicating a non-linear increase of basal plane spacing with compatibilizer extent.

Tensile properties of composites with increasing compatibilizer fraction have been detailed in Fig. (2). The modulus first increased, but later on decreased owing to plasticization of the matrix at higher weight fractions of com- 

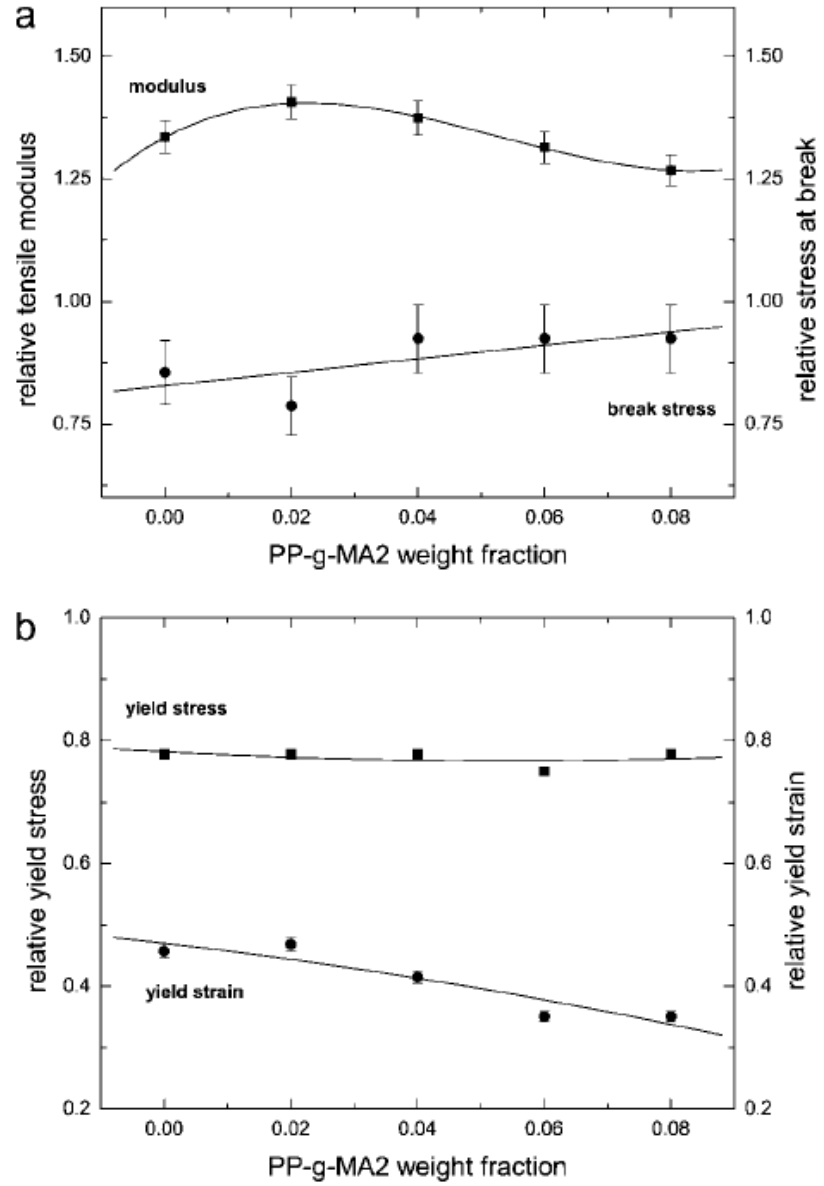

Fig. (2). (a) Relative tensile modulus and stress at break and (b) relative yield stress and strain of the polypropylene nanocomposites with increasing amount of compatibilizer. Reproduced from reference 26 with permission from Wiley.

patibilizer. There seemed also a balance between the filler exfoliation and matrix plasticization on increasing the compatibilizer amount. Stress at break was observed to increase owing to similar plasticization effect. Yield strain of the composites decreased indicating the presence of brittleness and incomplete filler exfoliation. The oxygen permeation through the composites as a function of compatibilizer fraction is depicted in Fig. (3). There was practically no change in the oxygen permeation as a function of increasing compatibilizer content. One reason for this could be nonintercalation of compatibilizer in the interlayers, but it was not true as observed from X-ray diffraction studies. Thus, the earlier mentioned balance between the improvement of oxygen barrier by filler delamination owing to increase in compatibilizer content and increase in permeation owing to mismatch between the compatibilizer and filler surface modification was observed to play a role. The thermal properties of the composites, on the other hand, were not deteriorated by the presence of even $8 \mathrm{wt} \%$ of the compatibilizer in the system.

The other route of organophilization of the filler surface without polarizing the polymer matrix may be expected to eliminate the unfavorable interactions between the compatibilizer chains and the filer surface modifications. Fig. (4) shows a representation of montmorillonite platelets modified with trioctadecylmethylammonium and tetraoctadecylammonium ions [29]. As mentioned above, the increased chain density as well as chain length in the filler modification can reduce the attractive forces between the platelets as the distance between them is increased. Apart from that, a mentioned earlier, it is also important to ascertain the complete ion exchange as well as filler surface free from any excess surface modification as these factors also affect the composite microstructure.

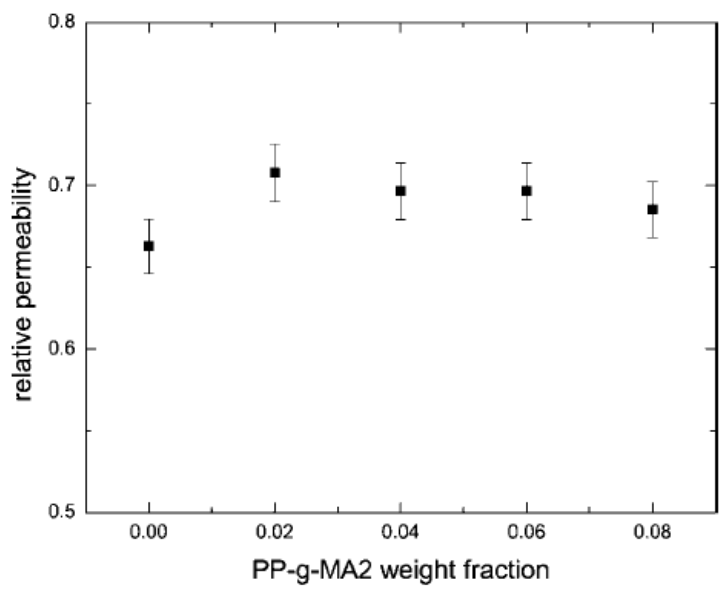

Fig. (3). Oxygen permeation through the polypropylene nanocomposites with increasing amount of compatibilizer. Reproduced from reference 26 with permission from Wiley.

In a representative study [30], polypropylene nanocomposites without the use of conventionally used compatibilizers were reported. The filler surface modifications included octadecyltrimethylammonium (C18), dioctadecyldimethylammonium (2C18), trioctadecylmethylammonium (3C18), benzylhexadecyldimethylammonium (BzC16) and docosyltriethylammonium (C22). Montmorillonites with two different cation exchange capacities (Cloisite with $880 \mu \mathrm{eqg}^{-1}$ and Nanofil with $680 \mu \mathrm{eqg}^{-1}$ ) were also used. Fig. (5) shows the impact of increasing chain density in the surface modification on the permeation properties of $3 \mathrm{vol} \%$ polypropylene nanocomposites. It is clearly visible that increasing basal plane spacing in the filler on increasing filler modification chain density had a significant effect on the permeation performance of the nanocomposites. The increased basal plane spacing in the filler decreased the attractive forces between the platelets and made the fillers more susceptible to exfoliate when sheared at high temperature with the polymer during melt mixing. The cation exchange capacity also had an influence on the permeation behavior as the higher cation exchange capacity filler led to better oxygen permeation resistance. This is owing to the fact that higher cation exchange capacity means lower area per cation available for the filler modification on the surface, which thus helps to increase the angle of the modification molecules with the surface subsequently increasing the basal plane spacing. The oxygen permeation also decreased as a function of filler volume fraction as shown in Fig. (6). A reduction of $35 \%$ in the oxygen permeation in the composite containing $3 \mathrm{vol} \%$ of the dioctadecyldimethylammonium modified filler was observed as compared to pure polymer. The oxygen permeation decrease was observed to level off at $3 \mathrm{vol} \%$ filler fraction as 


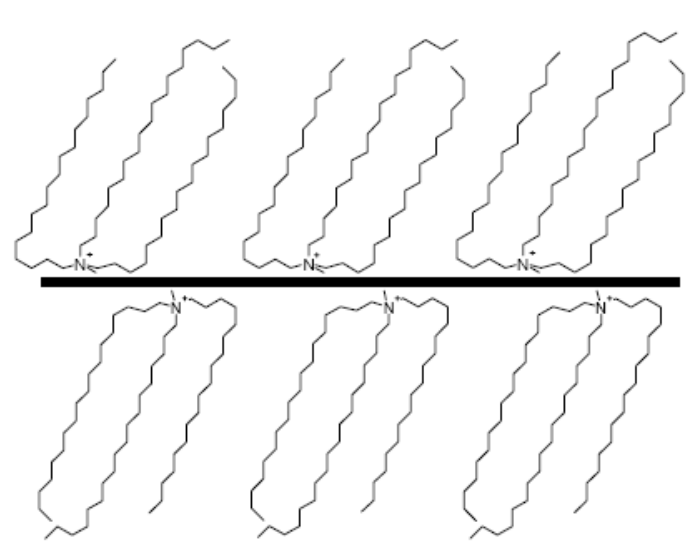

(a)

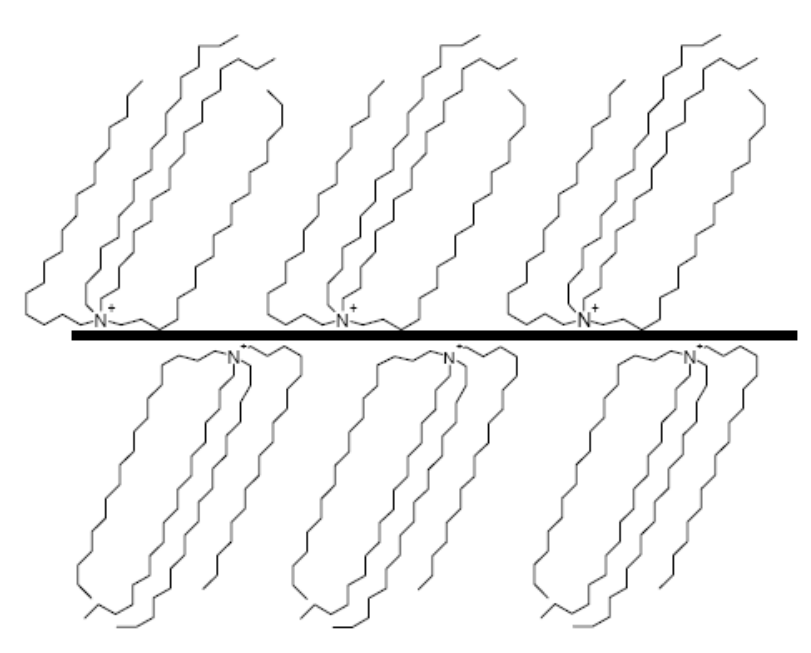

(b)

Fig. (4). Representation of montmorillonite platelets modified with (a) trioctadecylmethylammonium and (b) tetraoctadecylammonium ions. Reproduced from reference 29 with permission from Nova Science Publishers.

the increased amount of the filler did not lead to further improvement in oxygen barrier performance. The dotted line in Fig. (6) also represents the comparison of the experimental values and theoretical predictions. Considering that the platelets are aligned in the composite, the average filler aspect ratio was observed to be roughly 30 . But, as the filler platelets are generally misaligned in the composites, the assumption of aligned platelets does not hold true and one should consider the case of completely misaligned platelets. By considering this, an average aspect ratio of filler platelets was observed to be 100 . The decreases in the oxygen permeation as well as theoretical prediction of average aspect ratio of 100 clearly indicate that some extent of filler delamination must have taken place to affect the oxygen permeation of the composites significantly. Table $\mathbf{2}$ further elaborates the oxygen permeation properties of polypropylene nanocomposites with other modified fillers and for the fillers with different cation exchange capacities. Worth mentioning is also the effect of increasing the chain length of the surface modification molecules. Composite modified with C18 modification was observed to have oxygen permeation value of $74 \mathrm{~cm}^{3} \cdot \mu \mathrm{m} \cdot \mathrm{m}^{-2} \cdot \mathrm{d}^{-1} \cdot \mathrm{mmHg}^{-1}$ whereas the composite with $\mathrm{C} 22$ modification had oxygen permeation reduced to 62 $\mathrm{cm}^{3} \cdot \mu \mathrm{m} \cdot \mathrm{m}^{-2} \cdot \mathrm{d}^{-1} \cdot \mathrm{mmHg}^{-1}$ indicating by just increasing the chain length slightly, a significant improvement in the filler delamination and hence oxygen permeation performance could be achieved.

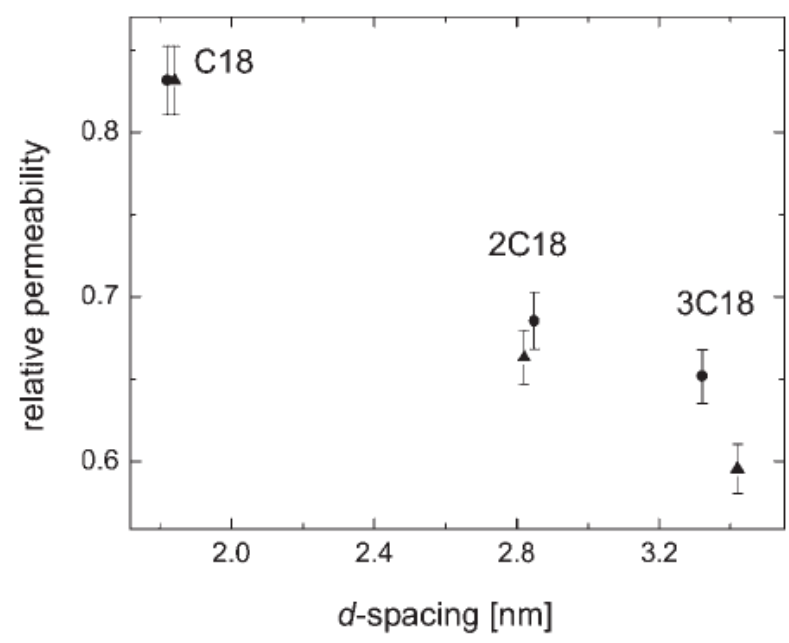

Fig. (5). Impact of increasing chain density in the filler surface modification on the oxygen permeation of polypropylene nanocomposites. Reproduced from reference 30 with permission from Wiley.

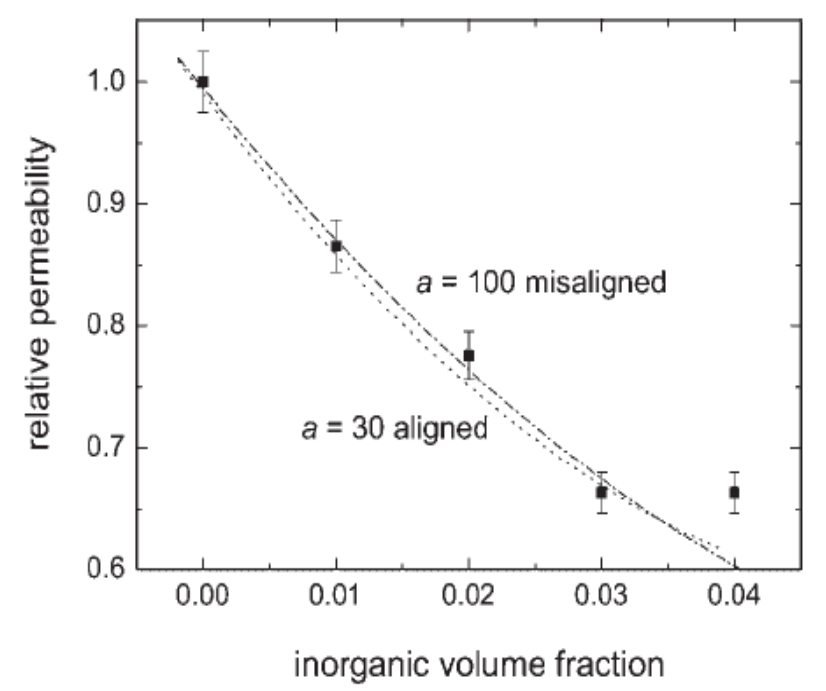

Fig. (6). Oxygen permeation of polypropylene nanocomposites as a function of filler volume fraction. The filler was modified with dioctadecyldimethylammonium ions. Reproduced from reference 30 with permission from Wiley.

Fig. (7) also shows the TEM micrograph of the 3 vol\% dioctadecyldimethylammonium modified clay - polypropylene nanocomposite. The morphology of the composite was observed to be mixed with a portion of the filler exfoliated as single layers, along with the presence of filler tactoids with 2-3 platelets together and thicker tactoids. This confirms the earlier notion that a partial exfoliation of the filler did take place even without the addition of conventionally used compatibilizer.

The clay platelets were observed to be bent and folded, which also confirms the assumption of misaligned platelets 
Table 2. Oxygen Permeation Properties of 3 vol\% Polypropylene Nanocomposites with Different Modified Fillers and with Clays of Two Different Cation Exchange Capacities. Reproduced from Reference 30 with Permission from Wiley

\begin{tabular}{|c|c|c|}
\hline \multirow[t]{2}{*}{ Organic cation } & \multicolumn{2}{|c|}{ Permeability Coefficient $\mathrm{cm}^{3} \cdot \mu \mathrm{m} \cdot \mathrm{m}^{-2} \cdot \mathrm{d}^{-1} \cdot \mathrm{mmHg}^{-1}$} \\
\hline & Cloisite & Nanofil \\
\hline Neat PP & 89 & 89 \\
\hline $\mathrm{C} 18 \mathrm{~N}+$ & 74 & 74 \\
\hline $2 \mathrm{C} 18 \mathrm{~N}+$ & 59 & 61 \\
\hline $3 \mathrm{C} 18 \mathrm{~N}+$ & 53 & 58 \\
\hline $\mathrm{BzC} 16 \mathrm{~N}+$ & 60 & 68 \\
\hline $\mathrm{C} 22 \mathrm{~N}+$ & 62 & -- \\
\hline
\end{tabular}

considered for the calculation of average aspect ratio of platelets. Another thing to note here is that no intercalation was suggested in the X-ray diffraction as the filler diffraction peaks were not affected in the composites. But by the action of shear, it can still be expected that the filler tactoids get thinner which is also confirmed by the oxygen permeation and microscopy studies. Also, the properties improved for all the fillers owing to the fact that the fillers surface were ensured to be clean, the cation exchange was always controlled to be near to $100 \%$ and the polymer compounding temperatures and times were also optimized to avoid any thermal degradation.

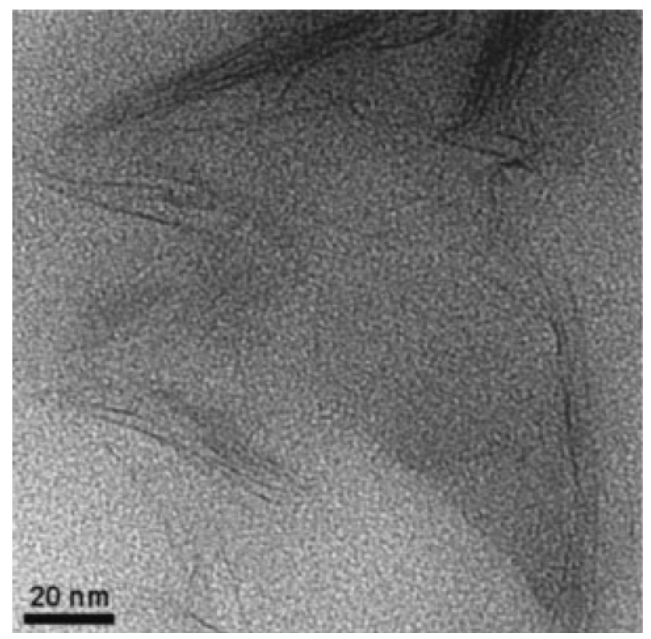

Fig. (7). TEM micrograph of the 3 vol\% dioctadecyldimethylammonium modified clay - polypropylene nanocomposite. Reproduced from reference 30 with permission from Wiley.

Mechanical properties of the composites were also observed to enhance [31]. Importance of increased basal plane spacing in the filler on the potential of filler exfoliation during compounding is further shown in Fig. (8a). The tensile modulus of the composites using fillers of two different cation exchange capacities was observed to slightly increase on enhancing the basal plane spacing, a finding similar to oxygen permeation behavior. Fig. (8b) also shows this behavior for $\mathrm{C} 18,2 \mathrm{C} 18$ and $3 \mathrm{C} 18$ based composites for both M680 (Nanofil) and M880 (Cloisite). The tensile modulus had a clear dependence on the extent of distance between the interlayers, which is related to their potential of exfoliation in the polymer during compounding. Tables $\mathbf{3}$ and $\mathbf{4}$ also show the detailed tensile behavior of composite with differ-
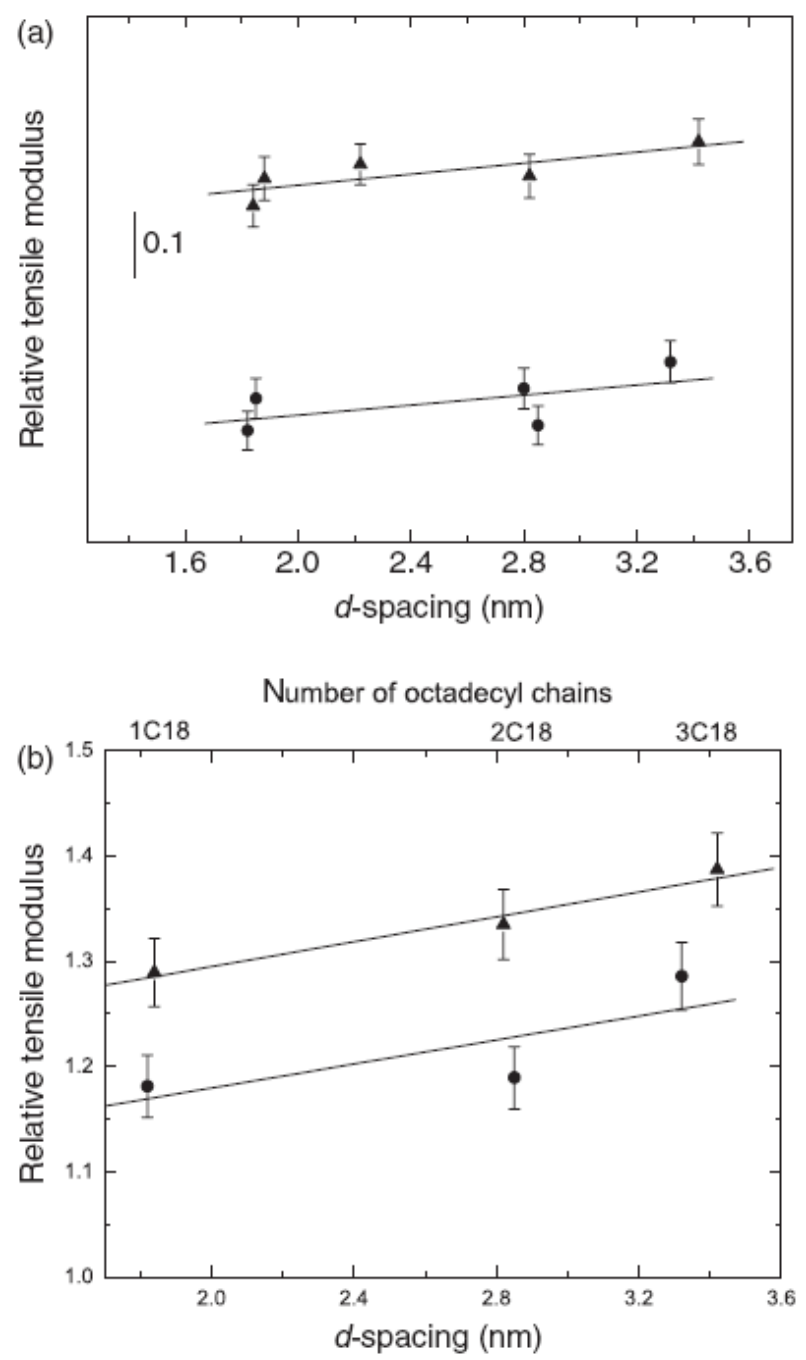

Fig. (8). (a) Relative tensile modulus of polypropylene nanocomposites as a function of basal plane spacing in the composites and (b) correlation of relative tensile modulus of the composites and basal plane spacing of the filler in composite as a function of number of octadecyl chains in the modification. $\mathbf{\Delta}$ : M880, $\mathbf{O}$ : M680. Reproduced from reference 31 with permission from Sage Publishers. 
Table 3. Mechanical Properties of Polypropylene Composites with 3 vol\% of Modified Filler for Cloisite M880. Reproduced from Reference 31 with Permission from Sage Publishers

\begin{tabular}{|c|c|c|c|c|}
\hline Filler & $\begin{array}{c}\text { Tensile Modulus }{ }^{\mathrm{a}} \\
\text { MPa }\end{array}$ & $\begin{array}{c}\text { Yield Stress }^{\mathrm{b}} \\
\text { MPa }\end{array}$ & $\begin{array}{c}\text { Yield Strain }^{\mathbf{c}} \\
(\%)\end{array}$ & $\begin{array}{c}\text { Stress at Break }{ }^{\mathrm{d}} \\
\text { MPA }\end{array}$ \\
\hline Neat PP & 1510 & 36 & 9.4 & 29 \\
\hline $\mathrm{C} 18 \cdot \mathrm{M} 880$ & 1947 & 31 & 5.6 & 29 \\
\hline $2 \mathrm{C} 18 \cdot \mathrm{M} 880$ & 2016 & 28 & 4.3 & 25 \\
\hline $3 \mathrm{C} 18 \cdot \mathrm{M} 880$ & 2095 & 23 & 3.0 & 21 \\
\hline $\mathrm{BzC} 16 \bullet \mathrm{M} 880$ & 2010 & 30 & 5.3 & 25 \\
\hline $2 \mathrm{C} 12 / 2 \mathrm{C} 18 \cdot \mathrm{M} 880$ & 2043 & 29 & 4.7 & 28 \\
\hline
\end{tabular}

${ }^{\mathrm{a}}$ Relative probable error $5 \%$.

${ }^{\mathrm{b}}$ Relative probable error $2 \%$.

${ }^{\mathrm{c}}$ Relative probable error $5 \%$.

${ }^{\mathrm{d}}$ Relative probable error $15 \%$.

Table 4. Mechanical Properties of Polypropylene Composites with 3 vol\% of Modified Filler for Cloisite M680. Reproduced from Reference 31 with Permission from Sage Publishers

\begin{tabular}{|c|c|c|c|c|}
\hline Filler & $\begin{array}{c}\text { Tensile Modulus }^{\mathrm{a}} \\
\text { MPa }\end{array}$ & $\begin{array}{c}\text { Yield Stress }^{\mathbf{b}} \\
\text { MPa }\end{array}$ & $\begin{array}{c}\text { Yield Strain } \\
(\%)\end{array}$ & $\begin{array}{c}\text { Stress at Break }^{\mathrm{d}} \\
\text { MPA }\end{array}$ \\
\hline Neat PP & 1510 & 36 & 9.4 & 29 \\
\hline $\mathrm{C} 18 \cdot \mathrm{M} 680$ & 1784 & 30 & 5.2 & 27 \\
\hline $2 \mathrm{C} 18 \cdot \mathrm{M} 680$ & 1796 & 29 & 5.3 & 23 \\
\hline $3 \mathrm{C} 18 \cdot \mathrm{M} 680$ & 1942 & 25 & 2.8 & 22 \\
\hline $\mathrm{BzC} 16 \bullet \mathrm{M} 680$ & 1858 & 31 & 5.3 & 29 \\
\hline 2C12/2C18•M680 & 1881 & 30 & 5.0 & 26 \\
\hline
\end{tabular}

${ }^{\text {a }}$ Relative probable error $5 \%$.

${ }^{b}$ Relative probable error $2 \%$.

${ }^{\mathrm{c}}$ Relative probable error $5 \%$.

${ }^{\mathrm{d}}$ Relative probable error $15 \%$.

ent filler substrates. Apart from other modifications, a mixed brush of didodecyldimethylammonium and dioctadecyldimethylammonium $(2 \mathrm{C} 12 / 2 \mathrm{C} 18)$ was also generated on the surface of fillers in order to obtain information on possible phase separation of the mono-brush modifications from the polymer. The increase in modulus in all the cases leads to the indication of partial exfoliation of the filler. The decrease in other mechanical properties as compared to pure polymer indicate incomplete exfoliation of filler, brittleness of polymer due to the presence of residual filler tactoids, stain hardening of the polymer chains intercalated in the filler interlayers etc. The tensile modulus was also observed to decreases almost linearly as a function of filler volume fraction as shown in Fig. (9) for dioctadecyldimethylammonium modified filler (M880) polymer system. At $4 \mathrm{vol} \%$ fraction of the filler, the tensile modulus increase by $45 \%$ as compared to pure polypropylene.

The presence of clay can also change the crystallinity of polymer in the composite, therefore, it is important to ascertain this effect so that the improvement in the composite properties can be appropriately attributed to different factors. As observed in Table 5, increasing the amount of clay in the polymer composites, the clay did not have any influence on crystallization and melting behavior of the polymer in the composites. Melt enthalpy and thus the degree of crystallin- ity were also unchanged. Thus, the influence of volume fraction on the gas permeation and mechanical properties can be attributed completely to the partial delamination of the filler.

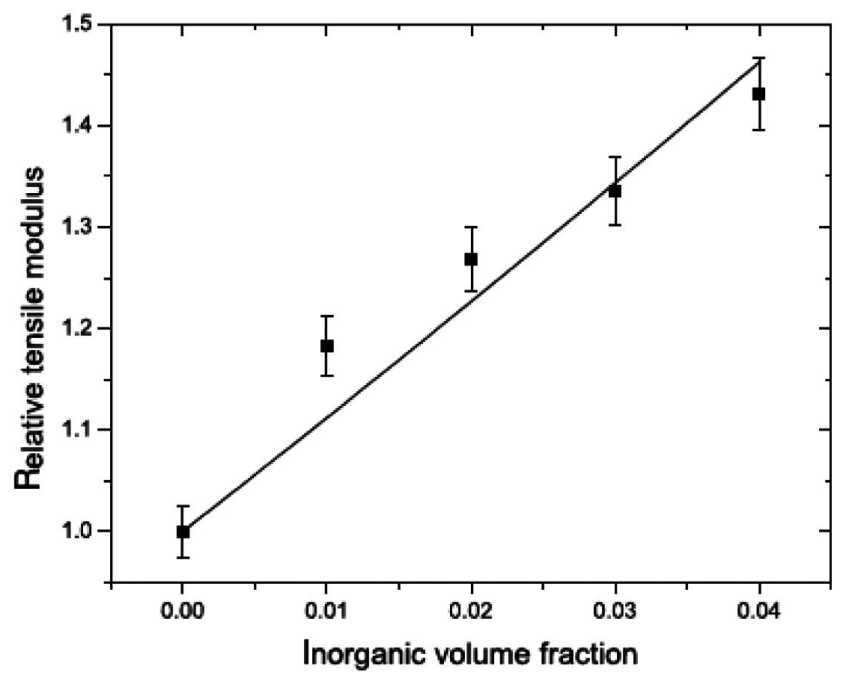

Fig. (9). Mechanical properties of the polypropylene nanocomposites with dioctadecyldimethylammonium modified filler (M880) as a function of its fraction. Reproduced from reference 31 with permission from Sage Publishers. 
Table 5. Calorimetric Behavior of the Polymer in Dioctadecyldimethylammonium Modified Filler - Polypropylene Nanocomposites Containing Different Filler Volume Fractions

\begin{tabular}{|c|c|c|c|c|c|c|}
\hline $\begin{array}{c}\text { Inorganic } \\
\text { volume fraction }\end{array}$ & $\begin{array}{c}\mathbf{T}_{\mathrm{m}, \text { onset }}{ }^{\mathrm{a}} \\
{ }^{\circ} \mathbf{C}\end{array}$ & $\begin{array}{l}\mathbf{T}_{\mathbf{m}}{ }^{\mathbf{b}} \\
{ }^{\circ} \mathbf{C}\end{array}$ & $\begin{array}{c}\Delta \mathbf{H}_{\mathrm{m} \text { polymer }} \\
\mathrm{J} / \mathrm{g}\end{array}$ & $\begin{array}{c}\text { Crystallinity }^{\mathrm{c}} \\
\mathbf{X}_{\mathrm{c}}\end{array}$ & $\begin{array}{c}\mathbf{T}_{\mathbf{c}, \text { onset }}{ }^{\mathbf{d}} \\
{ }^{\circ} \mathbf{C}\end{array}$ & $\begin{array}{l}\mathbf{T}_{\mathbf{c}}{ }^{\mathbf{e}} \\
{ }^{\circ} \mathbf{C}\end{array}$ \\
\hline 0.00 & 152 & 162 & 96 & 0.58 & 114 & 112 \\
\hline 0.01 & 153 & 162 & 95 & 0.58 & 115 & 112 \\
\hline 0.02 & 152 & 162 & 95 & 0.58 & 116 & 112 \\
\hline 0.03 & 152 & 163 & 94 & 0.57 & 115 & 112 \\
\hline 0.04 & 153 & 164 & 96 & 0.57 & 116 & 112 \\
\hline
\end{tabular}

a onset melting temperature.

peak melt temperature.

cdegree of crystallinity calculated using $\Delta \mathrm{H}$ of $100 \%$ crystalline $\mathrm{PP}=165 \mathrm{~J} / \mathrm{g}$

donset crystallization temperature.

'peak crystallization temperature.

\section{NANOCOMPOSITES WITH IMIDAZOLIUM BASED FILLER MODIFICATIONS}

As stated earlier, the ammonium ion based filler surface modifications have onset of degradation near to the compounding temperatures generally used for the synthesis of polypropylene nanocomposites, thus, one has to be careful while deciding compounding temperatures and time. Use of thermally stable medications has also been reported to circumvent this limitation [32-34]. In one such study, imidazolium based modification 1-decyl-2-methyl-3-octadecylimidazolium bromide was synthesized and exchanged on the surface of the montmorillonite platelets [32]. Composites with different volume fraction of this filler were then generated and characterized for their properties. Fig. (10) shows the oxygen permeation properties of the composites as a function of filler volume fraction. The performance of both ammonium and imidazolium modified montmorillonite systems has been showed. It was observed that the imidazolium based nanocomposites had better performance than the ammonium based composites owing to better thermal stability which would have eliminated the thermal degradation of the organic modification during compounding and its subsequent reaction with the polymer matrix. Even a small extent of thermal damage to the organic modification can be detrimental to the sensitive barrier properties which are affected by the interface between the polymer and filler. The thermogravimetric analysis studies on the imidazolium and ammonium modified montmorillonites revealed that the onset as well as peak degradation temperatures were shifted to higher temperatures in the case of imidazolium modification. The onset of degradation in the case of imidazolium muddied filler was $50^{\circ} \mathrm{C}$ higher than the corresponding ammonium modified filler, whereas his difference was $35^{\circ} \mathrm{C}$ in the case of peak degradation temperature. The dynamic thermogravimetric analysis also revealed that the amount of weight loss was more in the case of ammonium system as compared to imidazolium ions during the same amount of time. Though the difference in the weigh loss during this period of time was not significantly different, but the thermal degradation of even a small extent of surface modification molecules can change the interface between the polymer and filler, which affects the barrier properties more dearly. A decrease of $45 \%$ in the oxygen permeation at $4 \mathrm{vol} \%$ filler was observed in imidazolium system as compared to $35 \%$ decrease imidazolium system as compared to $35 \%$ decrease in the ammonium system. Also, the ammonium system was observed to level off at $3 \mathrm{vol} \%$, whereas the imidazolium system showed more linear decrease even after 3 vol $\%$ filler fraction. Another thing to note here is that the basal plane spacing in the imidazolium modified filler was lower as compared to ammonium modified filler owing to lower area of cross-section of imidazolium ions. Thus, the oxygen permeation was significantly better even in the case when basal plane spacing was lower. By increasing the chain length and chain density in the modification, further improvement in the oxygen barrier performance can be expected.

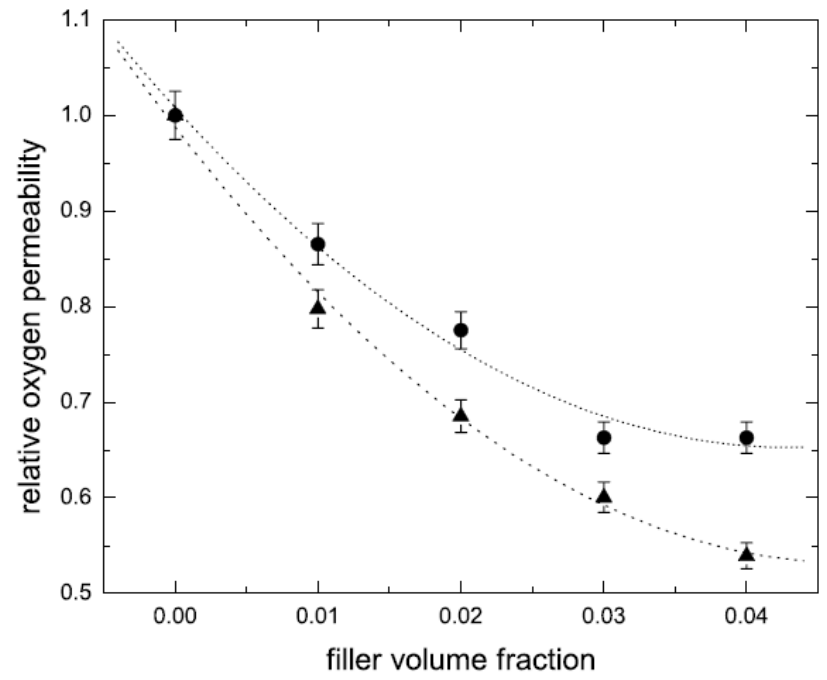

Fig. (10). Oxygen permeation of polypropylene nanocomposites with increasing fractions of filler modified with imidazolium ions ( $\Delta$ ) compared with ammonium modified filler based composites $(\bullet)$. Reproduced from reference 32 with permission of Elsevier.

Fig. (11) also shows the transmission electron micrographs of the polypropylene nanocomposites with 3 vol\% of the imidazolium modified filler. The filler platelets were observed to be partially exfoliated with the presence of mixed morphology by the virtue of exfoliated platelets as well as tactoids with varying thicknesses. Even though the basal plane spacing of the imidazolium modified filler was 

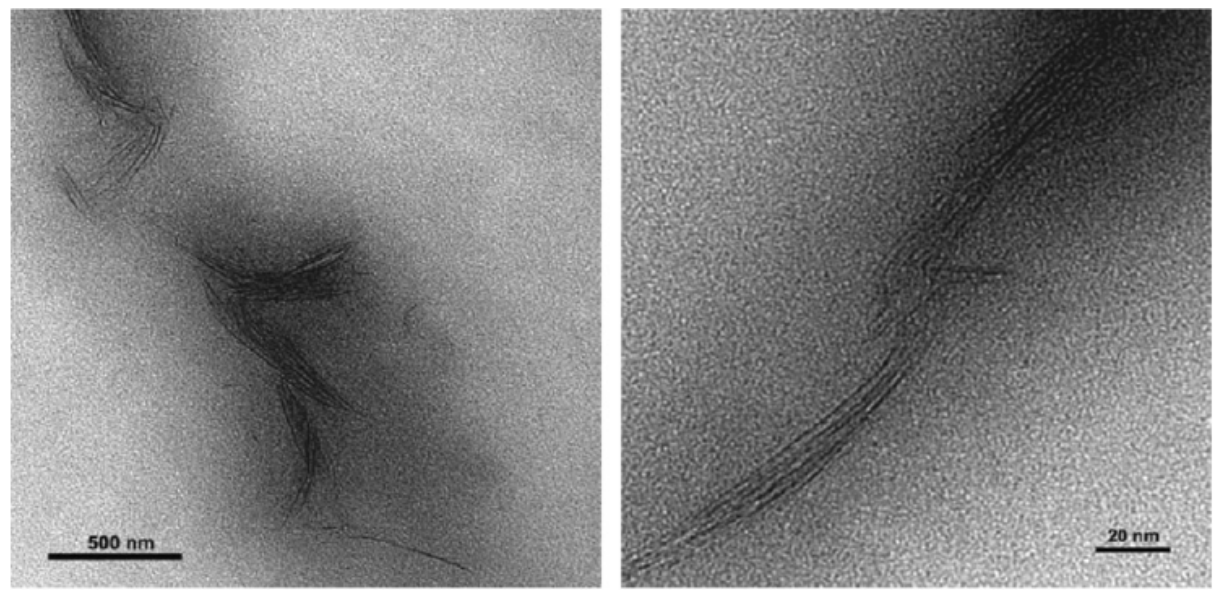

Fig. (11). TEM images of polypropylene nanocomposites with 3 vol\% imidazolium modified filler. Reproduced from reference 32 with permission of Elsevier.

low, even then partial exfoliation of the filler still took place. Similar to the ammonium system presented in last section, in this case too, there was no increase in the basal plane spacing of filler in the composite, but the tactoids could be reduced by shear in the compounder as represented by microscopy analysis and oxygen permeation properties. The tensile modulus of the composites was also observed to improve significantly. An increase of $35 \%$ in the modulus as compared to pure polypropylene at $4 \mathrm{vol} \%$ filler fraction was observed. The improvement was not as high as observed in the case of dioctadecyldimethylammonium modified filler owing to the low basal plane spacing of the imidazolium filler, as stated earlier. The properties of the nanocomposites were thus observed to be a result of two factors: improved thermal stability and lower extent of filler exfoliation owing to lower basal plane spacing. Fig. (12) also shows the correlation between the decrease in the relative oxygen permeability and increase in the relative tensile modulus of the imidazolium nanocomposites as a function of filler volume fraction. A good correlation exited between the two, indicating synergistic improvement in the properties. The imidazolium modified filler was also tested for its effect on the crystallinity of polypropylene in the composite. Similar to ammonium based modification, the inclusion of imidazolium treated montmorillonite did not change the crystallinity of the polymer in the processing conditions used.

The use of compatibilizers in combination with imidazolium modified montmorillonites was also reported [35]. Same compatibilizers as discussed in the case of ammonium modified montmorillonite systems were used. Fig. (13) shows the X-ray diffractograms of the pure imidazolium filler and $3 \mathrm{vol} \%$ composites with and without $2 \mathrm{wt} \%$ of compatibilizers. The basal plane spacing of the fillers was only marginally improved by the addition of compatibilizers partially owing to the low initial basal plane spacing of imidazolium modified montmorillonite. However, the increase was a function of polarity of the compatibilizers, as reported earlier. In the case of most polar compatibilizer PP-b-PPG, the basal plane spacing of the filler in composite was observed to be $2.51 \mathrm{~nm}$ as compared to $2.24 \mathrm{~nm}$ for the modified filler. However, the microscopy analysis indicates that though complete exfoliation of the filler did not take place, the tactoid thickness was nonetheless reduced and the filler was partially exfoliated.

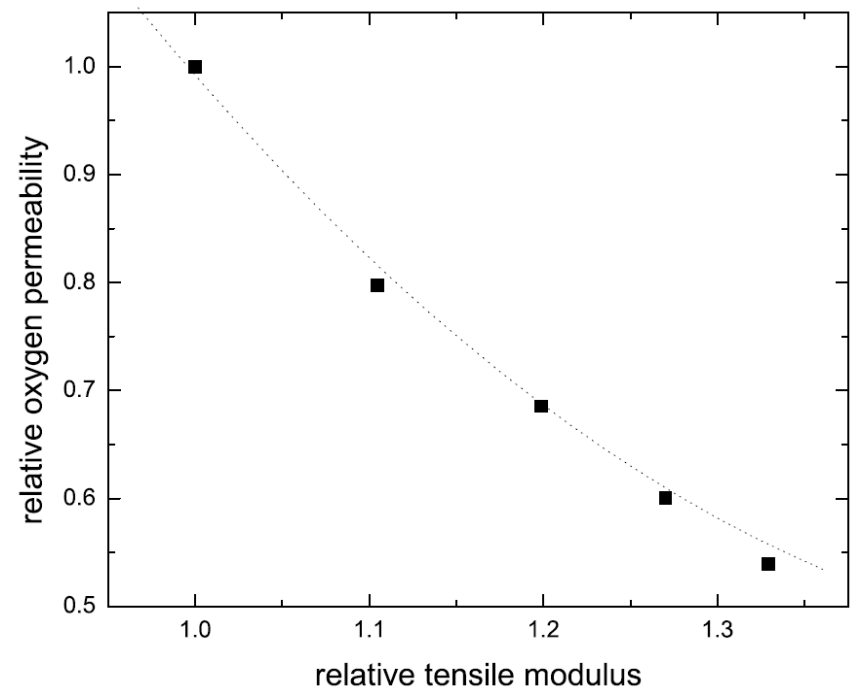

Fig. (12). Correlation between the decrease in the relative oxygen permeability and increase in the relative tensile modulus as a function of filler volume fraction. Reproduced from reference 32 with permission of Elsevier.

Table $\mathbf{6}$ shows the tensile properties of the compatibilized nanocomposites with filler volume fraction fixed at $3 \%$. All the compatibilizers were observed to increase the tensile modulus of the composites as compared to the composite without compatibilizer owing to increased extent of exfoliation on addition of compatibilizers. A weak plasticization of the polymer matrix was also indicated by the increase in the yield strain of the composites with compatibilizer as compared to the composite without compatibilizer. Other tensile properties like yield stress and the stress at break were also observed to be almost unchanged as the composite without compatibilizer indicating the presence of brittleness and incomplete filler exfoliation. Oxygen permeation of pure polymers and polymer nanocomposites containing $3 \mathrm{vol} \%$ filler modified with imidazolium ions with and without 2 $w t \%$ of various compatibilizers is also shown in Table 7 . The permeation through the composite films containing compatibilizer decreased as compared to the pure polymers but the decrease was either lesser or same as the composite without any compatibilizer. This behavior was already reported in the 


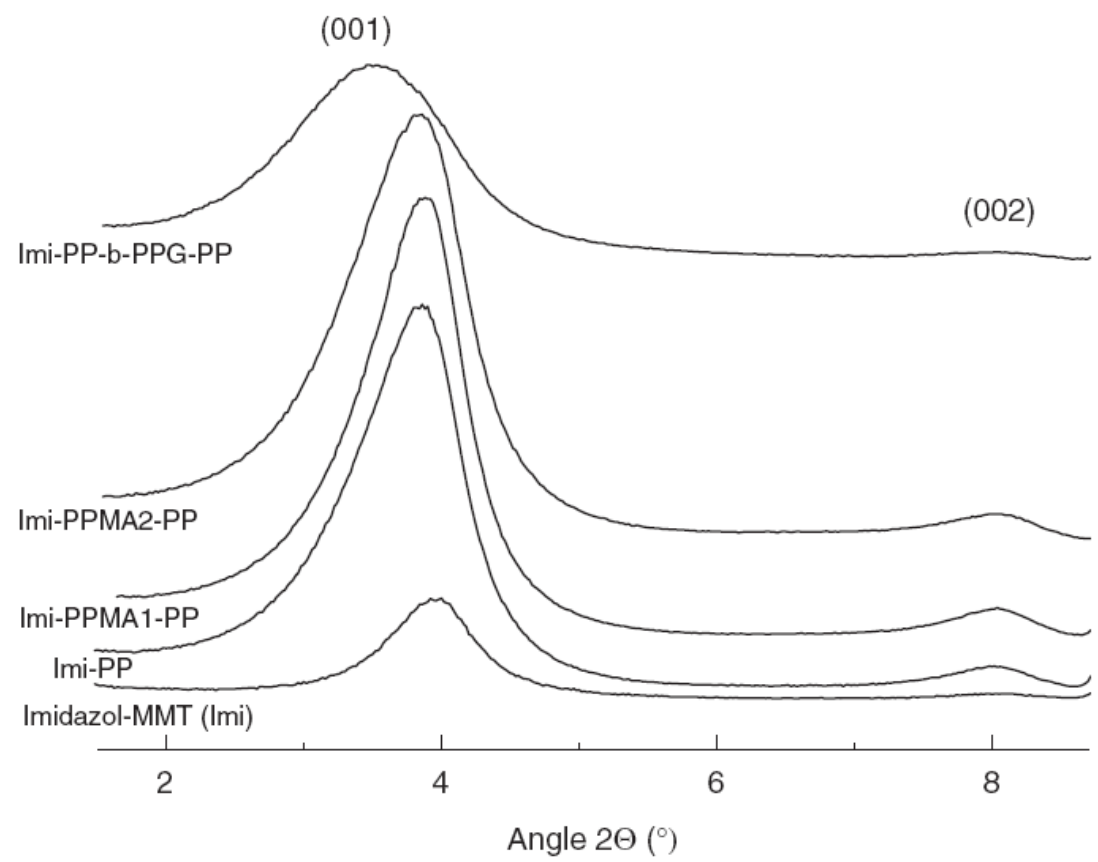

Fig. (13). X-ray diffractograms of the polypropylene nanocomposites with 3 vol\% imidazolium modified filler and 2 wt $\%$ of various compatibilizers. The diffraction patterns of pure filler as well as composite without compatibilizer have also been shown. Reproduced from reference 35 with permission from Sage Publishers.

Table 6. Tensile Properties of Pure Polymers and Polymer Nanocomposites Containing 3 vol\% Filler Modified with Imidazolium Ions with and without 2 wt\% of Various Compatibilizers. Reproduced from Reference 35 with Permission from Sage Publishers

\begin{tabular}{|c|c|c|c|c|}
\hline $\begin{array}{c}\text { Compatibilizer } \\
(\mathbf{2} \text { wt\%) }\end{array}$ & $\begin{array}{c}\text { Tensile Modulus } \\
\text { MPa }\end{array}$ & $\begin{array}{c}\text { Yield Stress }^{\mathbf{b}} \\
\text { MPa }\end{array}$ & $\begin{array}{c}\text { Yield Strain }^{\mathbf{c}} \\
\text { (\%) }\end{array}$ & $\begin{array}{c}\text { Stress at Break }^{\mathbf{d}} \\
\text { MPA }\end{array}$ \\
\hline \hline Pure PP & 1510 & 36 & 10.5 & 29 \\
\hline PP + PP-g-MA2 & 1463 & 33 & 4.4 & 23 \\
\hline No compatibilizer & 1918 & 26 & 5.5 & 24 \\
\hline PP-g-MA1 & 2039 & 26 & 5.8 & 25 \\
\hline PP-g-MA2 & 2023 & 27 & 5.5 & 22 \\
\hline PP-b-PPG & 1993 & 26 & & 25 \\
\hline
\end{tabular}

${ }^{\mathrm{a}}$ Relative probable error $5 \%$.

${ }^{\mathrm{b}}$ Relative probable error $2 \%$.

${ }^{\mathrm{c}}$ Relative probable error $5 \%$.

${ }^{\mathrm{d}}$ Relative probable error $15 \%$.

case of polypropylene nanocomposites with ammonium modified montmorillonites [26]. As the blend of polypropylene and the compatibilizer without clay did not have significant effect on the permeation properties, and the composite of polymer and clay has reduction in the oxygen permeation, therefore, the increase in the oxygen permeation in the polymer-compatibilizer-clay system can only be due to interactions between the clay and compatibilizer. As reported earlier, the incompatibility of the polar compatibilizer chains with the apolar surface modification chains leads to the generation of microvoids at the interface which affect the sensitive permeation properties negatively. Thus the enhancement in filler exfoliation by the addition of compatibilizer is deteriorated by this incompatibility.
The impact of compatibilizer on the thermal performance of the polymer nanocomposites is also necessary owing to its low molecular weight. Also, as incorporation of only $2 \mathrm{wt} \%$ of the compatibilizer is observed to impact the mechanical and permeation properties significantly, therefore, it may be possible that the thermal performance is also affected. Fig. (14) shows the thermogravimetric analysis of pure PP, PP-gMA2, imidazolium modified montmorillonite and $3 \mathrm{vol} \%$ polypropylene nanocomposite with $2 \mathrm{wt} \%$ of PP-g-MA2 compatibilizer. It was observed that the addition of compatibilizer did not degrade the thermal behavior of the composite. The thermal degradation behavior of the composite was indicative of the synergism between the thermal behaviors of organic and inorganic components of the composite. 
Table 7. Oxygen Permeation of Pure Polymers and Polymer Nanocomposites Containing 3 vol\% Filler Modified with Imidazolium Ions with and without 2 wt\% of Various Compatibilizers. Reproduced from Reference 35 with Permission from Sage Publishers

\begin{tabular}{|c|c|}
\hline Compatibilizer (2 wt\%) & Permeability coefficient $\left(\mathbf{c m}^{\mathbf{3}} \mathbf{\mu} \mathbf{m} / \mathbf{m}^{2} \mathbf{~ d a y ~} \mathbf{~ m m H g}\right)$ \\
\hline \hline Pure PP & 89 \\
\hline PP + PP-g-MA2 & 83 \\
\hline No compatibilizer & 57 \\
\hline PP-g-MA1 & 69 \\
\hline PP-g-MA2 & 61 \\
\hline PP-b-PPG & 78 \\
\hline
\end{tabular}

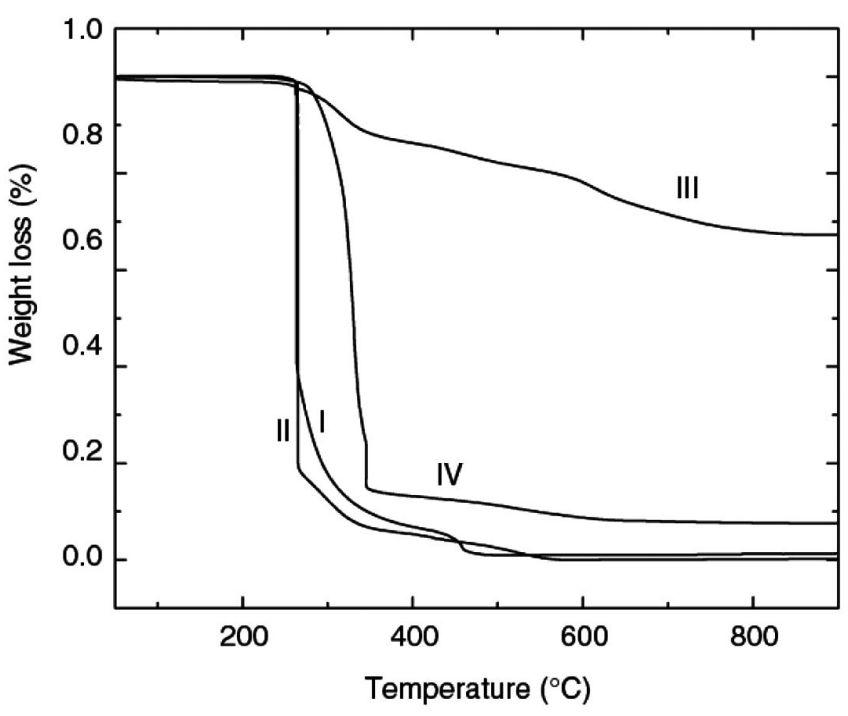

Fig. (14). Thermogravimetric analysis of pure PP (I), PP-g-MA2 (II), imidazolium modified montmorillonite (III) and 3 vol\% polypropylene nanocomposite with $2 \mathrm{wt} \%$ of PP-g-MA2 compatibilizer (IV). Reproduced from reference 35 with permission from Sage Publishers.

\section{MODELING OF POLYPROPYLENE NANOCOM- POSITES}

As mentioned earlier, the modeling of nanocomposite properties is required to design the systems based on requirement and thus to control the microstructure development and composite properties [36-38]. Various micromechanical models have been developed over the years to predict the mechanical response of the particulate composites. Halpin Tasai model has received special attention, though it is required to modify the model to fit with the polymer nanocomposites technology. The assumptions of complete filler alignment, perfect adhesion at interface etc. do not hold true for the case of polypropylene nanocomposites. Incomplete exfoliation of the filler is another factor which needs to be incorporated in the model. The model has recently been modified in order to accommodate the effect of incomplete exfoliation and misorientation of the filler, but the effect of imperfect adhesion at the surface still needs to be incorporated [39-40].

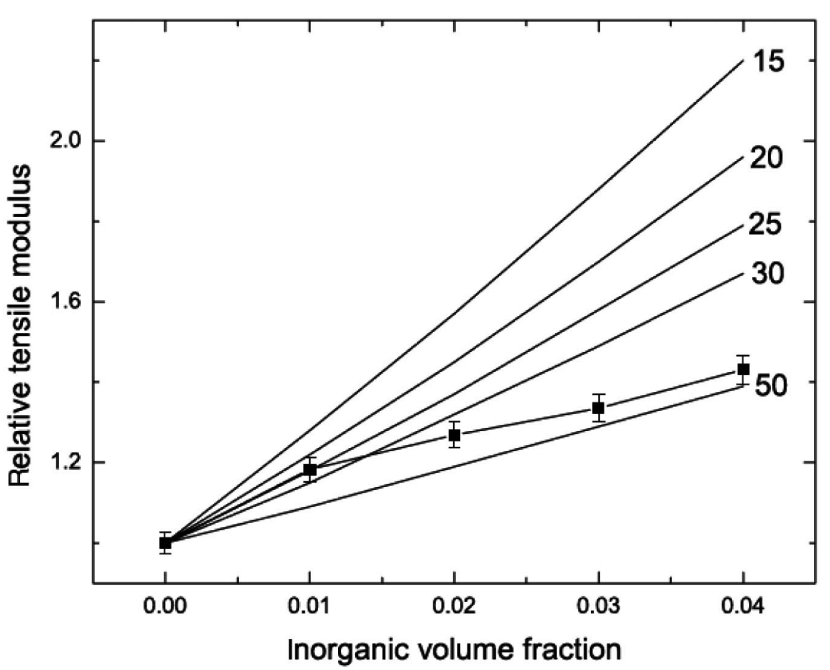

Fig. (15). Relative tensile modulus of polypropylene nanocomposites at different inorganic volume fraction of dioctadecyldimethylammonium modified montmorillonite ( $\mathbf{\square}$ :- experimental) compared with the values considering different number of platelets in the stack. Reproduced from reference 31 with permission from Sage Publishers.

Fig. (15) shows the relative tensile modulus of polypropylene nanocomposites at different inorganic volume fraction of dioctadecyldimethylammonium modified montmorillonite ( $\mathbf{\square}$ :- experimental) compared with the theoretical lines representing different number of platelets in the stack generated by modified Halpin Tasai models incorporating the effects of incomplete filler exfoliation as well as filler misalignment. The composites with $1 \mathrm{vol} \%$ of the filler, the average number of platelets in the stack was observed to be between 20-25, which increases with increasing the filler volume fraction. 20-25 platelets per stack generate a too low value for the aspect ratio as compared to roughly $100 \mathrm{ob}-$ tained from finite element modeling of the oxygen permeation properties. However, a significant limitation of the micro-mechanical models is the assumption of bonding between the phases at interface, which is not the case for polypropylene nanocomposites.

Design of experiments methodology using factorial and mixture designs has also emerged as an alternative tool for the prediction of composite properties [41]. The various fac- 


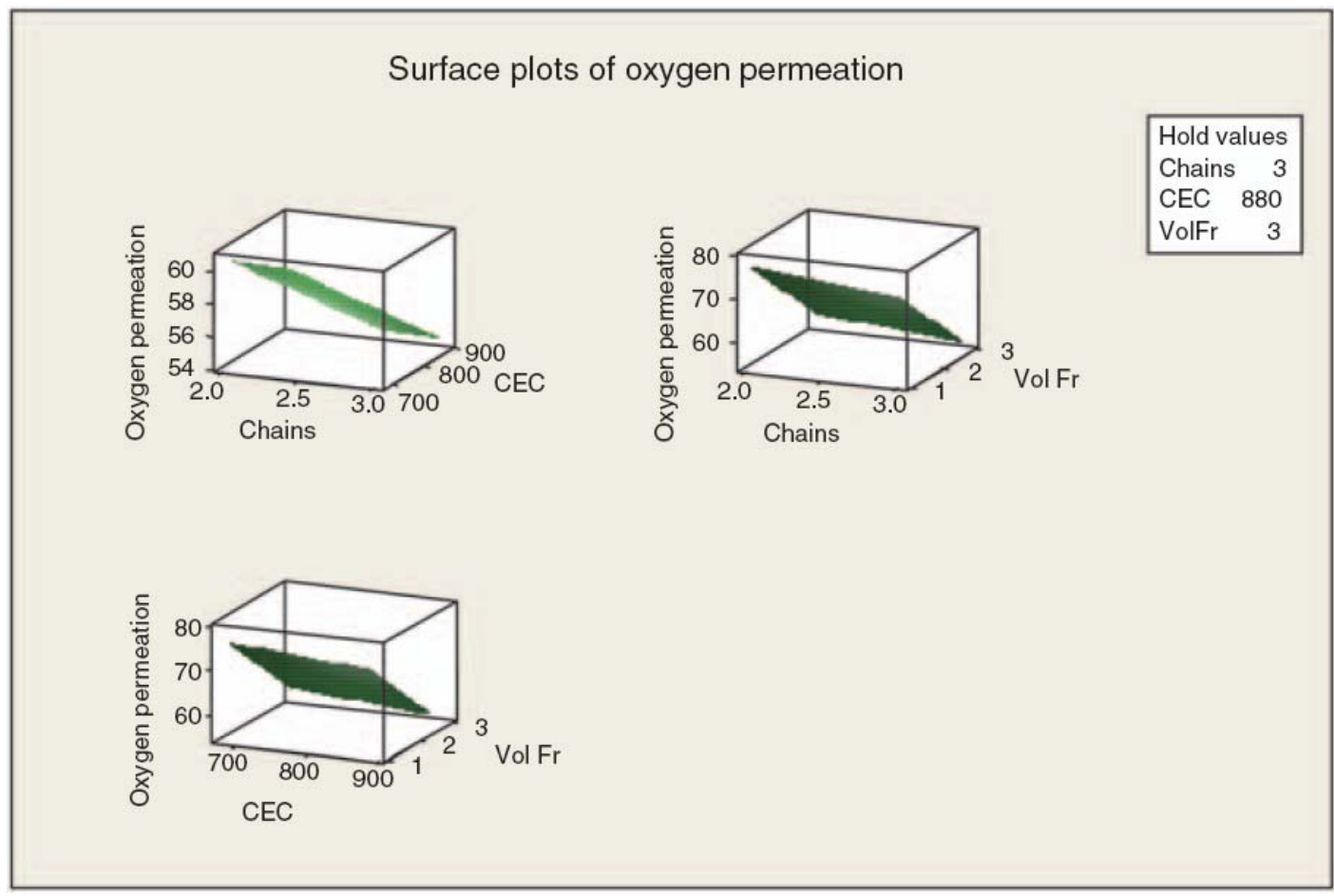

Fig. (16). Surface plots of the oxygen permeation through polypropylene nanocomposites (using dioctadecyldimethylammonium modified montmorillonite) as a function of two factors of the design, while the third is kept constant. Reproduced from reference 41 with permission from Sage Publishers.

tors studied for the factorial design are volume fraction of inorganic clay, cation exchange capacity of the montmorillonite (MMT) substrate, and number of octadecyl chains in the ammonium modification ion exchanged on the clay surface. The constrained mixtures design includes the components as weight percent of polymer matrix, organic modification, and inorganic filler as compared to the total weight of the mixture. The mixtures design for compatibilized nanocomposites is also studied by using the components weight percent of polymer, organically modified clay, and the compatibilizer. Unlike conventional models which depend on oversimplified assumptions, which are not applicable in reality, these models do not suffer from these limitations and can still predict the composite properties using a set of simple equations. Fig. (16) shows a representative surface plot for the factorial design for prediction of oxygen permeation of polypropylene nanocomposites. A basic set of experimental results were input in the model equations and to check the resulting model, the predicted oxygen permeation properties were also checked experimentally. The experimental and theoretical values were observed to narrowly match with each other thus confirming the superiority of the model.

\section{ADVANCED FILLER SURFACE MODIFICATIONS}

The increased chain length in the surface modification was observed to have significant effect on the microstructure and properties of polypropylene nanocomposites [30]. Thus, it is of interest to exchange much longer surface modification chains on the filler surface which can help to totally eliminate the attractive forces between the platelets. But exchange of long surface modification chains is not straightforward owing to their solubility concerns. Also, long alkyl ammonium ions are not generally available. To circumvent these limitations, a number of different routes of advanced filler surface modification have been reported. The first method involves the exchange of reactive surface modifications on the surface and their subsequent chemical reactions with long alkyl chain molecules to increase the basal plane spacing [42]. An example is shown in Fig. (17a) where the filler surface is first modified with modifications with terminal $\mathrm{OH}$ groups. These groups can then be esterified with long chain acids to improve the interlayer spacing. A more specific example is shown in Fig. (17b) where the reaction of benzyldibutyl(2-hydroxyethyl)ammonium chloride $(\mathrm{Bz} 1 \mathrm{OH})$ with long chain dotriacontanoic acid is depicted. It was observed that when the montmorillonite modified with benzyl(2-hydroxyethyl)methyloctadecylammonium chloride $(\mathrm{BzC} 18 \mathrm{OH})$ was reacted with dotriacontanoic acid, the basal pane spacing of the filler increased from $2.06 \mathrm{~nm}$ before esterification reaction to $2.96 \mathrm{~nm}$ after esterification reaction. Much better improvement in the basal plane spacing was observed when number of $\mathrm{OH}$ groups in the surface modification molecules were increased. As a result, when bis(2hydroxyethyl)methyl hydrogenated tallow ammonium $(\mathrm{C} 182 \mathrm{OH})$ modified montmorillonite was reacted with dotriacontanoic acid, the basal plane spacing was observed to increase to $5.27 \mathrm{~nm}$ after esterification reaction as compared to $1.79 \mathrm{~nm}$ for the montmorillonite before reaction.

The second method is more versatile method as it allows the generation of oligomeric chains of different polymers on the surface of the filler and the length of these chains can also be controlled by the use of living polymerization conditions [43]. This method involves the immobilization of either a monomer (Fig. 18a) or an initiator on the filler surface which can then be used for co-polymerization with the externally added monomer (Fig. 18b). This way, the polymer chains can either graft to the filler surface or can graft from the surface. The filler surface is generally only partially 


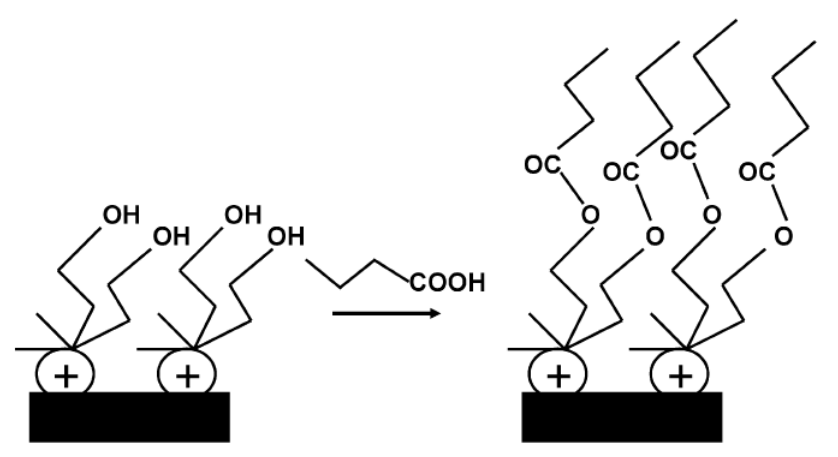

(a)

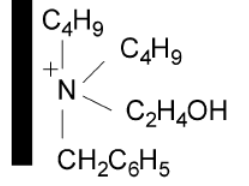

(benzyl dibutyl hydroxyethyl ammonium- cloisite)

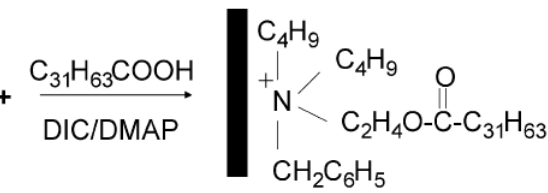

(b)

Fig. (17). (a) Representation of surface esterification reaction and (b) schematic of surface esterification reaction of montmorillonite modified with benzyldibutyl(2-hydroxyethyl)ammonium chloride $(\mathrm{Bz} 1 \mathrm{OH})$ with long chain dotriacontanoic acid. Reproduced from reference 42 with permission from Elsevier.
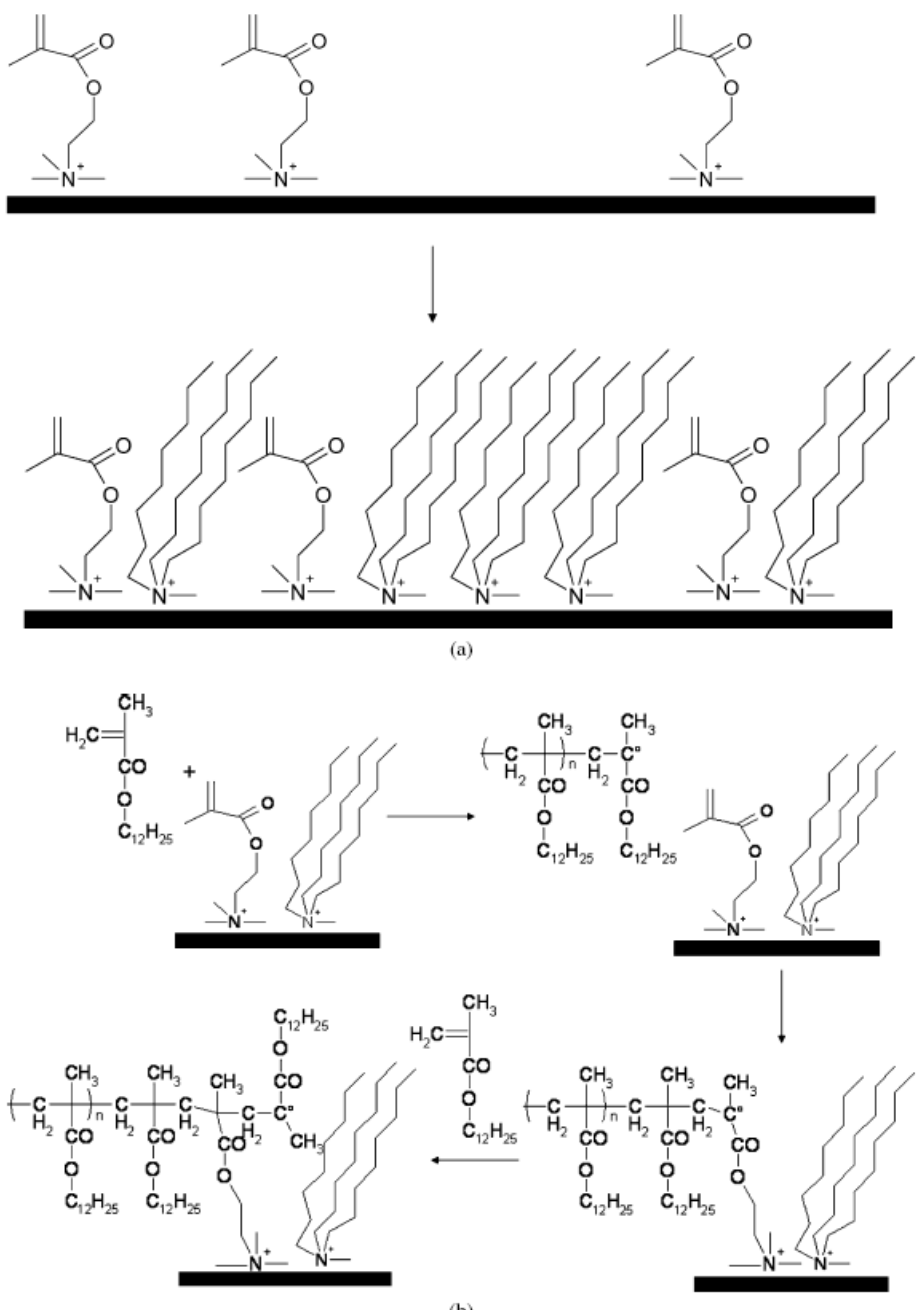

(b)

Fig. (18). (a) Schematic of two step modification of filler surface with methyltrioctylammonium and methacryloxyethyltrimethylammonium (MOETMA) and (b) schematic of dodecylmethacrylate polymerization with methyltrioctylammonium and MOETMA ionically bound to the clay surface. Reproduced from reference 43 with permission from Elsevier. 


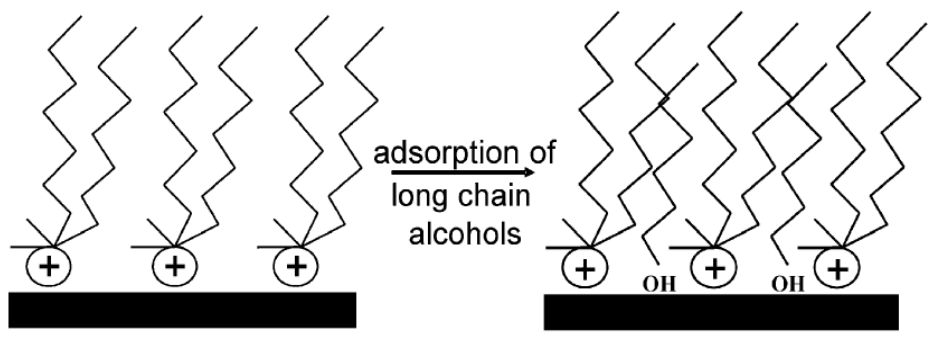

Fig. (19). Schematic of physical adsorption on the clay surface. Reproduced from reference 44 with permission from Elsevier.

covered with the initiator or monomer molecules as the complete coverage of the surface with these molecules would generate a very large amount of chains attached to the surface and this may lead to phase separation with the polymer when the filler is compounded with it. It was observed that the filler basal plane spacing could be increased in the range of $3.4 \mathrm{~nm}-6.4 \mathrm{~nm}$ by using these polymer grafting trials either to the surface or from the surface.

Another method to improve the potential of filler exfoliation in the polymer matrix is the physical adsorption of long chain polar molecules on the surface of already modified montmorillonites [44]. Cross-sectional area of the ammonium ion cation exchanged on the montmorillonite surface is generally smaller than the area available per cation on the montmorillonite (medium cation exchange capacity). This leads to partially uncovered spaces or patches on the filler surface which, thus, hinders the complete organophilization of the filler surface and the forces holding the platelets together still remain. One solution is to increase the chain density in the organic modification and the results have already been reported in the earlier sections. The other possibility is to physically adsorb long chain molecules on the surface of montmorillonite already modified with conventional modification as shown in Fig. (19). These molecules (e.g., long alkyl chain alcohols) can adsorb physically in between the gaps generated after modification with ammonium ions by forming $\mathrm{H}$ bonds. These bonds can be generated with the $\mathrm{OH}$ groups present either in the inside structure of clay crystals or on the edges of the platelets. The adsorption has also been reported to take place on the pre-adsorbed water molecules in the clay interlayers. It was observed that even the high molecular weight polymer like poly(vinylpyrrolidone) could also be adsorbed on the surface. The adsorption not only organophilized the filler platelets better by reducing electrostatic forces of attraction among them, but it was also observed that the thermal stability of the modified filler also significantly improved.

The modified fillers generated by these techniques represent high potential fillers with strong potential of easy and complete delamination in the polypropylene matrix.

\section{ACKNOWLEDGEMENT}

None declared.

\section{CONFLICT OF INTEREST}

None declared.

\section{REFERENCES}

[1] Yano, K.; Usuki, A.; Okada, A.; Kurauchi, T.; Kamigaito, O. Synthesis and properties of polyimide-clay hybrid. J. Polym. Sci. Part A: Polym. Chem., 1993, 31, 2493-2498.
[2] Kojima, Y.; Fukumori, K.; Usuki, A.; Okada, A.; Kurauchi, T. Gas permeabilities in rubber-clay hybrid. J. Mater. Sci. Lett., 1993, 12, 889-890.

[3] Lan, T.; Kaviratna, P.D.; Pinnavaia, T.J. On the nature of polyimidie-clay hybrid composites. Chem. Mater., 1994, 6, 573-575.

[4] Lan, T.; Pinnavaia, T.J. Clay-reinforced epoxy nanocomposites. Chem. Mater., 1994, 6, 2216-2219.

[5] Burnside, S.D.; Giannelis, E.P. Synthesis and properties of new poly(dimethyl siloxane) nanocomposites. Chem. Mater., 1995, 7, 1597-1600.

[6] Wang, Z.; Pinnavaia, T.J. Nanolayer reinforcement of elastomeric polyurethane. Chem. Mater., 1998, 10,3769-3771.

[7] Messersmith, P.B.; Giannelis, E.P. Synthesis and barrier properties of poly( $\varepsilon$-caprolactone)-layered silicate nanocomposites. J. Polym. Sci. Part A: Polym. Chem., 1995, 33, 1047-1057.

[8] Yano, K.; Usuki, A.; Okada, A. Synthesis and properties of polyimide-clay hybrid films. J. Polym. Sci. Part A: Polym. Chem., 1997, 35, 2289-2294.

[9] Vaia, R.A.; Ishii, H.; Giannelis, E.P. Synthesis and properties of two-dimensional nanostructures by direct intercalation of polymer melts in layered silicates. Chem. Mater., 1993, 5, 1694-1696.

[10] Mehrotra, V.; Giannelis, E.P. Conducting molecular multilayers: intercalation of conjugated polymers in layered media. Mater. Res. Soc. Symp. Proc., 1990, 171, 39-44.

[11] Vaia, R.A.; Giannelis, E.P. Lattice of polymer melt intercalation in organically-modified layered silicates. Macromolecules, 1997, 30, 7990-7999.

[12] Balazs, A.C.; Singh, C.; Zhulina, E.; Lyatskaya, Y. Modeling the phase behavior of polymer/clay nanocomposites. Acc. Chem. Res., 1999, 32, 651-657.

[13] Ginzburg, V.V.; Singh, C.; Balazs, A.C. Theoretical phase diagrams of polymer/clay composites. The role of grafted organic modifiers. Macromolecules, 2000, 33, 1089-1099.

[14] Balazs, A.C.; Singh, C.; Zhulina E. Modeling the interactions between polymers and clay surfaces through self-consistent-field theory. Macromolecules, 1998, 31, 8370-8381.

[15] Kato, M.; Usuki, A.; Okada, A. Synthesis of polypropylene oligomer-clay intercalation compounds. J, Appl. Polym. Sci., 1997, $66,1781-1785$

[16] Kawasumi, M.; Hasegawa, N.; Kato, M.; Usuki, A.; Okada, A. Preparation and mechanical properties of polypropylene-clay hybrids. Macromolecules, 1997, 30, 6333-6338.

[17] Usuki, A.; Kato, M.; Okada, A.; Kurauchi, T. Synthesis of polypropylene-clay hybrid. J. Appl. Polym. Sci., 1997, 63, 137-138.

[18] Hasegawa, N.; Kawasumi, M.; Kato, M.; Usuki, A.; Okada, A. Preparation and mechanical properties of polypropylene-clay hybrids using a maleic anhydride-modified polypropylene oligomer. J. Appl. Polym. Sci., 1998, 67, 87-92.

[19] Reichert, P.; Nitz, H.; Klinke, S.; Brandsch, R.; Thomann, R.; Muelhaupt, R. Poly(propylene)/organoclay nanocomposite formation: Influence of compatibilizer functionality and organoclay modification. Macromol. Mater. Eng., 2000, 275, 8-17.

[20] Manias, E.; Touny, A.; Wu, L.; Strawhecker, K.; Lu, B.; Chung, T.C. Polypropylene/montmorillonite nanocomposites. Review of synthetic routes and materials properties. Chem. Mater., 2001, 13, 3516-3523.

[21] Zhang, Q.; Fu, Q.; Jiang, L.; Lei, Y. Preparation and properties of polypropylene/montmorillonite layered nanocomposites. Polym. Int., 2000, 49, 1561-1564.

[22] Oya, A.; Kurokawa, Y.; Yasuda, H. Factors controlling mechanical properties of clay mineral/polypropylene nanocomposites. J. Mater. Sci., 2000, 35, 1045-1050. 
[23] Xu, W.; Liang, G.; Wang, W.; Tang, S.; He, P.; Pan, W.P. PP-PPg-MAH-Org-MMT nanocomposites. I. Intercalation behavior and microstructure. J. Appl. Polym. Sci., 2003, 88, 3225-3231.

[24] Ellis, T.S.; D'Angelo, J.S. Thermal and mechanical properties of a polypropylene nanocomposite. J. Appl. Polym. Sci., 2003, 90, $1639-1647$.

[25] Zhang, J.; Jiang, D.D.; Wilkie, C.A. Polyethylene and polypropylene nanocomposites based on a three component oligomericallymodified clay. Polym. Degrad. Stab., 2006, 91, 641-648.

[26] Mittal, V. Mechanical and gas permeation properties of compatibilized polypropylene-layered silicate nanocomposites. J. Appl. Polym. Sci., 2008, 107, 1350-1361.

[27] Osman, M.A.; Mittal, V.; Morbidelli, M.; Suter, U.W. Epoxylayered silicate nanocomposites and their gas permeation properties. Macromolecules, 2004, 37, 7250-7257.

[28] Osman, M.A.; Mittal, V.; Morbidelli, M.; Suter, U.W. Polyurethane adhesive nanocomposites as gas permeation barrier. Macromolecules, 2003, 36, 9851-9858.

[29] Mittal, V. In Polymer Nanocomposites: Advances in Filler Surface Modification Techniques, Mittal, V., Ed. Nova Science Publishers: New York, 2009; pp. 1-14.

[30] Osman, M.A.; Mittal, V.; Suter, U.W. Poly(propylene)-layered silicate nanocomposites: Gas permeation properties and clay exfoliation. Macromol. Chem. Phys., 2007, 208, 68-75.

[31] Mittal, V. Polypropylene-layered silicate nanocomposites: Filler matrix interactions and mechanical properties. J. Thermoplast. Compos. Mater., 2007, 20, 575-599.

[32] Mittal, V. Gas permeation and mechanical properties of polypropylene nanocomposites with thermally-stable imidazolium modified clay. Eur. Polym. J., 2007, 43, 3727-3736.

[33] Awad, W.H.; Gilman, J.W.; Nyden, M.; Harris, Jr. R.H.; Sutto, T.E.; Callahan, J. et al. Thermal degradation studies of alkylimidazolium salts and their application in nanocomposites. Thermochim. Acta, 2004, 409, 3-11.
[34] Zhu, J.; Morgan, A.B.; Lamelas, F.J.; Wilkie, C.A. Fire properties of polystyrene-clay nanocomposites. Chem. Mater., 2001, 13, 3774-80.

[35] Mittal, V. 2009. Polypropylene nanocomposites with thermallystable imidazolium modified clay: mechanical modeling and effect of compatibilizer. J. Thermoplastic Compos. Mater., [in print].

[36] Kerner, E.H. The elastic and thermo-elastic properties of composite media. Proc. Phys. Soc., 1956, B69(8), 808-813.

[37] Hashin, Z.; Shtrikman, S. A variational approach to the theory of the elastic behavior of multiphase materials. J. Mech. Phys. Solids, 1963, 11(2), 127-140.

[38] Halpin, J.C. Stiffness and expansion estimates for oriented short fiber composites. J. Compos. Mater., 1969, 3(4), 732-734.

[39] Fornes, T.D.; Paul, D.R. Modeling properties of nylon 6/clay nanocomposites using composite theories. Polymer, 2003, 44(17), 49935013.

[40] Brune, D.A.; Bicerano, J. Micromechanics of nanocomposites: Comparison of tensile and compressive elastic moduli, and prediction of effects of incomplete exfoliation and imperfect alignment on modulus. Polymer, 2002, 43(2), 369-387.

[41] Mittal, V. Modeling the behavior of polymer-layered silicate nanocomposites using factorial and mixture designs. J. Thermoplastic Compos. Mater., 2008, 21, 9-26.

[42] Mittal, V. Esterification reactions on the surface of layered silicate clay platelets. J. Colloid Interface Sci., 2007, 315, 135-141.

[43] Mittal, V. Polymer chains grafted "to" and "from" layered silicate clay platelets. J. Colloid Interface Sci., 2007, 314, 141-151.

[44] Mittal, V.; Herle, V. Physical adsorption of organic molecules on the surface of layered silicate clay platelets: A thermogravimetric study. J. Colloid Interface Sci., 2008, 327, 295-301.

(C) V. Mittal; Licensee Bentham Open.

This is an open access article licensed under the terms of the Creative Commons Attribution Non-Commercial License (http://creativecommons.org/licenses/by-nc/3.0/) which permits unrestricted, non-commercial use, distribution and reproduction in any medium, provided the work is properly cited. 